\title{
Mission Performance Analysis of a Conceptual Coaxial Rotorcraft for Air Taxi Applications
}

\author{
J. Enconniere ${ }^{\mathrm{a}, *}$, J. Ortiz-Carretero ${ }^{\mathrm{a}}$, V. Pachidis ${ }^{\mathrm{a}}$ \\ ${ }^{a}$ Cranfield University, College Rd, Cranfield, Bedfordshire MK43 OAL, UK
}

\begin{abstract}
The rotorcraft industry has recently shown a new interest in compound rotorcraft as a feasible alternative to tackle the rapid growth of civil aviation activities and associated environmental impact. Indeed, aircraft contribution to the global emissions of $\mathrm{CO}_{2}, \mathrm{NO}_{x}$, and noise are driving the development of innovative technologies and vehicles. At present, compound rotorcraft architectures are regarded by the industry as promising platforms that can potentially increase productivity at a reduced environmental cost. In order to quantify the benefits of compound rotorcraft, this paper details the performance analysis of a coaxial counterrotating rotor configuration with a pusher propeller. A comprehensive approach targeting the assessment of the aforementioned rotorcraft design for civil applications is presented herein. The methodology developed encompasses a rotorcraft flight dynamics simulation module and an engine performance module, coupled with a gaseous emissions prediction tool for environmental impact studies. They have been integrated together to constitute a standalone performance simulation framework and verified with the performance calculations of Harrington's "rotor 1" and the Sikorsky X2TD. The method is then applied to evaluate the performance of a conceptual coaxial rotorcraft, during a notional inter-city air taxi mission, in terms of cruise altitude, speed, and range, overall mission time and environmental impact. The several trade-offs between these parameters highlight the need for an integrated optimisation process. Besides, the concept demonstrates the benefits of the compound rotorcraft architecture with a best range speed reaching $90 \mathrm{~m} / \mathrm{s}$ leading to reduced response times and increase of round trips in a given time. As a consequence, operators will need fewer vehicles and heliports to cover the same areas. This outcome is highly attractive in the current growing market.
\end{abstract}

Keywords: rotorcraft, coaxial rotor, simulation, performance, mission analysis, gaseous emissions

\section{General Context}

The continuous rise in global energy demand, resulting inevitably in the depletion of fossil fuel, motivates the exploration for more efficient and sustainable transport alternatives. Although the aviation activity is a relatively small contributor to the global carbon dioxide $\left(\mathrm{CO}_{2}\right)$ footprint, with an estimated $2 \%$ share of the worldwide emissions [1, it is subject to increasing concerns from government authorities and international regulatory bodies. This is explained by the fast growth of the global aviation traffic with an average annual growth of $4 \%$ 22. The 2035 global traffic is forecasted to be twofold the one in 2016 making the aviation industry the most rapidly growing source of $\mathrm{CO}_{2}$ emissions. Moreover, aircraft contribute to climate change in more than $\mathrm{CO}_{2}$ emissions: Nitrogen-oxides $\left(\mathrm{NO}_{x}\right)$, water vapour, particulate matter (soot) are also emitted by aircraft engines. All emissions from aviation were estimated to represent approximately $5 \%$ of the global temperature rise in 2005 [3. $N O_{x}$ also severely impairs people's health when present in high concentration. A third critic directed to the aviation industry is its noise emissions. Indeed aircraft noise is

\footnotetext{
* Corresponding author

Email address: j.p.enconniere@cranfield.ac.uk (J. Enconniere)
} 
the most significant cause of adverse community reaction related to the operation and expansion of airports 4].

Thanks to their unique abilities, rotorcraft are seen in plethora of activities, encompassing homeland defence, search and rescue, law enforcement, and oil rig services, amongst others. These activities represent an annual average of about 1,500,000 flight hours, which may be considered small compared to the 10,000,000 hours flown by European commercial airlines. However, rotorcraft activities are often situated in the vicinity of densely populated areas. Additionally, those urban activities are expected to boom. Indeed, medical activities are meant to increase due to the development of advanced curing techniques and hospitals specialisation. Helicopters are seen as a quick and safe way to transport patients between hospitals [5]. Concurrently, the passenger transport/air taxi, which has been a marginal activity until recently, is expected to largely expand in the near future with a two to three-fold increase in the 2015-2020 period [6].

The Advisory Council for Aeronautics Research in Europe (ACARE) has established a set of specific environmental goals to be achieved by 2020 by the aviation industry, targeting a sustainable growth. The goals include, among others, a $50 \%$ reduction in $\mathrm{CO}_{2}$ emissions through reductions in fuel consumption and a $80 \%$ reduction in $N O_{x}$ emissions, all relative to the year 2000 technology level. Clarke 4 highlights three possible approaches to meet these targets: either the number of operations must be reduced, the type of aircraft must be changed, or the aircraft flight procedure must be modified. Considering the expected growth of the helicopter industry, the first proposition is not viable. According to Brooker [7, the time-scale required to develop a new aircraft concept from conception to certification is counted in decades (from 20 to 50 years). Therefore, the short-term ACARE VISION 2020 goals can only be answered with "ready-to-fly" technologies, close to certification. This is the case of the Sikorsky S-97 which had its maiden flight in 2015, following the X2 Technology ${ }^{T M}$ Demonstrator (X2TD) program (Figure 1] 8]. Although initially targeted for military activities, it would come with no surprise if a derivative concept is introduced for the civil market in the next decade. The S-97 type architecture is based on a coaxial lift-offset rotor with a pusher propeller similarly to Figure 1. The S-97 is expected to reach similar performance to the one the X2TD has shown: unprecedented cruise speeds, providing increased mission range while keeping efficient hovering capabilities 9. The aforementioned architecture also results in a more compact and manoeuvrable design, suitable for urban applications 10. Optimisation of flight procedures for the specific vehicle is also a key path to answer the short-terms goals and is important for the integration of new vehicle architectures in the global air traffic as their perceived performance depends largely on the way they are flown.

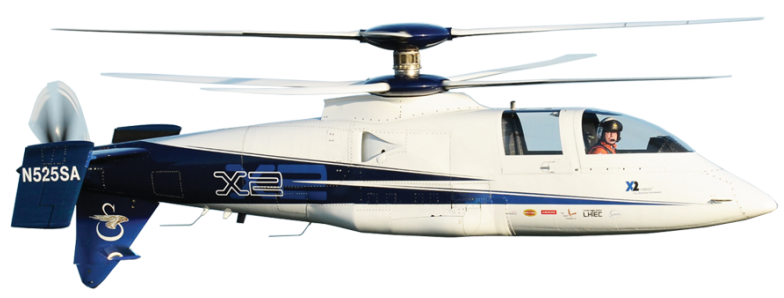

Figure 1: Sikorsky X2TD rotorcraft 8

Conventional helicopters experience several drawbacks. Firstly, an anti-torque system is required to counteract the one generated by the main rotor. For that purpose, most vehicles are equipped with a tail rotor which can represent up to $13 \%$ of the total power at hover [1]. The second handicap appears as the helicopter flies faster. The lateral cyclic pitch increases to counteract the lateral lift asymmetry. The retreating blades experience high incidence at low speed with possible large reverse flows. The advancing side of the rotor, on the other hand, can experience transonic flows. Stall boundaries are thus hit on both sides resulting in high drag and instabilities, limiting the maximum speed of conventional helicopters [12]. The technology demonstrated by the X2TD intends to bypass those issues with a coaxial rotor. The torque produced by the upper rotor is balanced by the lower rotor, therefore there is no need for an additional anti-torque system. In forward flight, the retreating side of the rotor is offloaded and the lateral equilibrium 
is obtained by balancing the rolling moment of both counter-rotating rotors, as illustrated in Figure 2 . The drag generated by the retreating side is significantly reduced whilst the advancing side is more efficiently used. Additionally, the rotor speed is reduced to keep the rotor tip Mach number of the advancing side below Mach 0.9 to limit transonic effects. At speed above $60 \mathrm{~m} / \mathrm{s}$, the X2TD operates its coaxial rotor in autorotation thanks to the rear mounted propeller acting as an auxiliary propulsive system (see Figure 1).

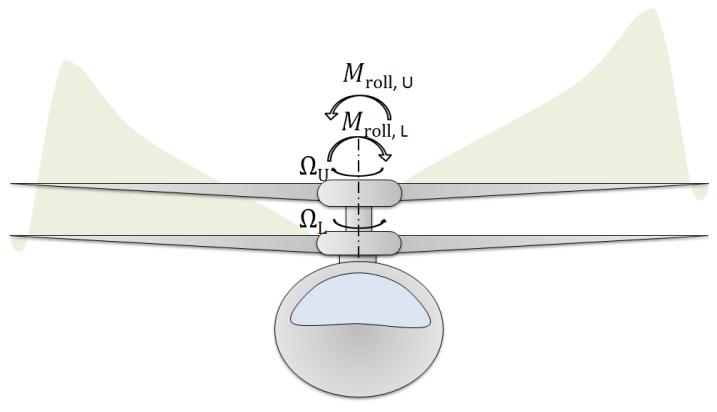

Figure 2: Lateral equilibrium concept of a coaxial helicopter in forward speed conditions, adapted from [13]

The analytical process followed to design the X2TD main rotor blade is detailed in [13]. A non-uniform inflow calibrated with the XH-59A isolated rotor deducted from flight test data and airfoil table look-up and stall models were specifically employed for the matter. The performance effects of rotor geometrical properties, lift-offset and pitch attitude were investigated in order to reach an "optimum" high speed rotor based on cumulative improvements starting from a XH-59A scale rotor. An approximate $60 \%$ increase in forward flight efficiency was calculated thanks to improved rotor characteristics (planform, twist, thickness, etc). The favourable effects of lift-offset and positive rotor shaft angle on the rotor load distribution were also highlighted.

Johnson [14] also studied the influence of lift-offset on several rotorcraft architectures using an aeromechanics analysis including advanced non-linear finite elements. The discussion is focused on the performance optimisation of the rotor for hover and high-speed cruise with discussions over the impact of rotor characteristics such as rotor spacing. In a later publication, Johnson 15 extends the discussion with the rotor design optimisation for hover and cruise speed conditions. The X2TD blades are compared with the optimised blades and show less efficiency, demonstrating the limitation of the method developed in [13. Although the lift-offset is fixed for the optimisation cases, its rotor weight effect is investigated with two empirical approaches. They show significant differences highlighting their respective limitations and the lack of knowledge on the subject.

\subsection{Scope of the Present Work}

Compound rotorcraft are expected to appear in the civil rotorcraft industry but little is known about their capabilities regarding their operational and environmental performance. Rotorcraft flight dynamics simulation models have shown in the past the capability to evaluate the performance of innovative technologies in a cost-effective manner [5, 16, 17.

Padfield 12 proposes a three-level hierarchy rotorcraft model based on their level of complexity. Within a level 1 modelling, a disk-like representation of the main rotor is incorporated along with linear blade aerodynamics. The wake-induced velocity at the rotors is expressed as a superposition of finite flow states within a first order dynamic inflow estimation. Level 2 refines the level 1 modelling, employing individual blade representation. Level 3 modelling encompasses the complete aeroelastic behaviour of the main rotor with unsteady, non-linear blade element aerodynamics and three-dimensional rotor wake-induced flow modelling [12. Levels 1 and 2 are suitable for the analysis of parametric trends well within the limits of the operational envelope. Therefore, a level 1 model can cater for environmental impact assessment without large computational overhead [5].

The aforementioned method is not specifically limited to conventional main rotor/tail rotor rotorcraft architectures and is applicable to any compound architecture. Therefore a multidisciplinary flight dynamics 
simulation framework is developed specifically for coaxial rotor with a pusher propeller configuration. It integrates a comprehensive mission analysis approach to account for the third point raised by Clarke [4. A gaseous emissions prediction method is also incorporated to cater for the environmental impact analysis. Noise emissions are not addressed in the presented work.

\section{Numerical Formulation}

\subsection{Overview}

The approach is based on the subdivision of several comprehensive modules which, when coupled together, define an effective rotorcraft simulation framework. This includes a Coaxial Rotorcraft Performance Model (CRPM) solving the non-linear system of equations for trim, coupled with an engine off-design performance analysis module [18] and a gaseous emissions prediction tool [19]. Finally, a flight path profile analysis module based on the World Geodetic System date 1984 (WGS 84) is also included 20. The whole framework is integrated within a mission analysis, estimating the unknown initial aircraft All-Up-Mass $(A U M)$ through an iterative process. Further discussion of each introduced module is detailed in the next subsections.

\subsection{Rotorcraft Performance Model}

The rotorcraft performance model is based on a flight mechanics code, designed to estimate steady state conditions, establishing overall force and moment balance for any given flight conditions. A simplified version of the Euler's equations for the kinematics of a rigid body is then defined and solved numerically through a Newton-Raphson iterative process. Each iteration needs a re-estimation of the aerodynamic forces and performance of each rotorcraft components, i.e. rotors, fuselage, wings, hubs, etc. The process eventually estimates the control inputs (collective, longitudinal cyclic, lateral cyclic for both counter-rotating rotors and collective for the propeller) in order to minimise the 3-dimensional forces and moments to reach a state of equilibrium.

The key subsystems of the modelled rotorcraft are the coaxial counter-rotating rotor and the rearmounted pusher propeller. The two rotors of the coaxial rotor system, strongly interact with each other, especially at hover/low-speed conditions. Therefore, the method employed needs to catch these interactions to some extent. The model implemented utilises steady-state linear Blade Element Momentum Theory in which each rotor is modelled as an infinite thin disk. Therefore, radial and azimuthal distribution of rotor aerodynamic loading are estimated and integrated to obtain the forces and moments experimented by the rotor's hub. The rotors flapping motion is calculated based on the centre spring equivalent rotor detailed by Padfield [12. The blades are nevertheless considered as rigid bodies. As for the propeller, it is considered fully rigid.

Although extensive documentation is available on coaxial rotor inflow models under axial flow (hover, axial flight) [21, 22, relatively little is available for forward flight. Therefore, the designed method is based on an analytical approach proposed by Yana et al. 222 and adapted for forward flight. The coaxial rotor model is shown in Figure 3 . Both rotors are considered identical for the study.

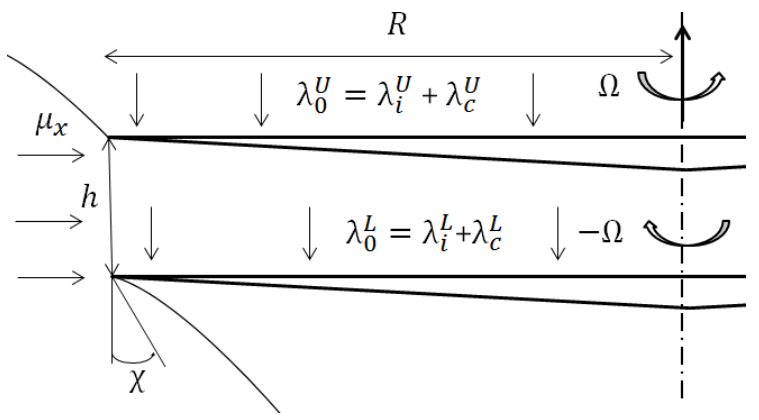

Figure 3: Coaxial rotor system in forward flight 
Having a low computational cost requirement in mind, the inflow model follows the Pitt \& Peters model 21], corrected to take into account the coaxial rotors' interactions to some extent. The correction is set to consider the lower rotor induced velocity as an equivalent climb speed for the upper rotor and vice versa for the upper rotor (Figure 3). The Pitt \& Peters inflow model takes the following form:

$$
\lambda(r, \psi)=\lambda_{0}\left(1+r \frac{15 \pi}{32} \tan (\chi) \cos (\psi)\right)
$$

where $\lambda_{0}$ is the uniform inflow estimated by momentum theory, $\psi$ is the azimuth angle and $\chi$ is the rotor skew angle $\left(\tan (\chi)=\frac{\mu_{x}}{\lambda_{0}^{L}}\right)$. This formulation of the inflow is applied to both counter-rotating rotors. The interactions between both rotors appear in the value $\lambda_{0}$ which differs between the upper rotor and the lower rotor. Indeed, the general form of the inflow equation given by the momentum theory can be written as:

$$
\lambda_{0}=\mu_{x} \tan (\alpha)+\frac{\lambda_{h}^{2}}{\sqrt{\mu_{x}^{2}+\lambda_{0}^{2}}}+\lambda_{c} \cos (\alpha)
$$

where $\lambda_{c}$ takes the following form:

$$
\begin{aligned}
& \lambda_{c}^{U}=\lambda_{c}+k^{L U} \lambda_{i}^{L} \Gamma^{L U}(\chi) \\
& \lambda_{c}^{L}=\lambda_{c}+k^{U L} \lambda_{i}^{U} \Gamma^{U L}(\chi)
\end{aligned}
$$

These two equations reflect the mentioned interactions between the two rotors. $\Gamma^{L U}(\chi)$ and $\Gamma^{U L}(\chi)$ reflect the attenuation of the interaction with speed and both take the following form $\Gamma(\chi)=\cos (\chi)$. $\chi$ is referred as the wake skew angle of the lower rotor. Although the wake of one rotor only impacts part of the second rotor, the method averages this effect over the complete rotor disc. The corrections factors $k^{L U}$ and $k^{U L}$ are defined as:

$$
\begin{aligned}
& k^{U L}=k_{0}\left(1-\left(\frac{d}{\sqrt{1+d^{2}}}\right)^{\gamma^{U L}}\right) \\
& k^{L U}=k_{0}\left(1+\left(\frac{d}{\sqrt{1+d^{2}}}\right)^{\gamma^{L U}}\right)
\end{aligned}
$$

These correction factors are a function of $d$, defined as the ratio between rotors spacing $h$ and rotor radius $R_{\text {rotor }} \gamma^{U L}$ and $\gamma^{L U}$ reflect the wake contraction as described in [22. A more sophisticated finite state inflow model like the one proposed by Nowak et al. 23. could be added in the future to increase the fidelity of the main rotor inflow model. It is based on the extension of the Pitt \& Peters inflow harmonic to unlimited number of harmonics. However, the aforementioned inflow calculation is computationally efficient and sufficiently accurate for performance studies.

The coaxial rotor wake is also interfering with other parts of the rotorcraft. It impacts not only on the fuselage but also on the rear wings and the propeller. The fuselage is modelled following Padfied's approach 12], defined with a representative surface. Concerning the wings, a similar method as the one introduced for the coaxial rotor is followed with the introduction of the function $\Gamma^{W}(\chi) . \Gamma^{W}(\chi)$ appears in the following expression:

$$
\mu_{z}^{W}=\mu_{z}+\lambda_{0}^{L} \Gamma^{W}(\chi)
$$

$\Gamma^{W}(\chi)$ is a constant when $\chi_{1}<\chi<\chi_{2}$, null otherwise. $\chi_{1}$ and $\chi_{2}$ are a function of the rotorcraft dimensions (rotor radius, wings positions...). As for the propeller, the theory employed follows the one introduced for the coaxial rotor. Both single and coaxial propeller can be modelled. Due to the relative size of the coaxial rotor hub and shaft compared with the fuselage, their drag component is accounted in the trimming process.

With conventional helicopters, there are four pilot controls: collective, lateral cyclic, longitudinal cyclic, and tail rotor collective to evaluate for flight trim equilibrium plus two aircraft variables such as pitch and roll. The particularity of the evaluated architecture allows for differential thrust, longitudinal moment, 
and lateral moment, the latter also called lift-offset. Therefore, there are seven pilot controls: mean and differential collective, lateral cyclic, and longitudinal cyclic for the coaxial rotor and one collective for the rear-mounted propeller. The complexity of the trimming process results in the need of three assumptions:

- The same longitudinal cyclic is set for both counter-rotating rotors.

- The rolling moment of each counter-rotating rotor must be specified.

- The aircraft variables are set within the rotorcraft performance tool.

The first point accounts for the differential longitudinal moment. Another option would have been to set the differential moment between the two rotors with a specification of the moments, such as the method followed for the differential lateral moment where the lateral lift-offset is particularised. The presence of the propeller results in the possibility of lift and thrust sharing. The third assumption specifies the aircraft pitch, roll, and sideslip. Roll and sideslip are kept null for every flight conditions, whilst the aircraft pitch is calculated as a function of the flight conditions (AUM, altitude, forward speed, and climb rate). The selection of the pitch attitude is allowed thanks to the presence of the coaxial rotor and the propeller which can share lift and propulsive force. These assumptions are further discussed in the section covering the evaluation of the Sikorsky X2TD performance.

\subsection{Engine Performance Model E6 Emissions Prediction}

As shown in Figure 5, an engine performance model is integrated into the framework. A reliable model is required to cater for the engine operating point at any flight conditions. The nature of the rotorcraft leads to substantial interaction between the propeller and the engine. Consequently, both the engine fuel flow and the engine residual thrust are calculated. The fuel flow is used to update the mass of the vehicle. The engine thrust appears in the rotorcraft trim calculation to find the state of equilibrium of the rotorcraft system. The engine performance model integrated is a Cranfield University "in-house" gas turbine performance simulation code called TURBOMATCH. It is a long-standing and validated tool capable of simulating any aero and industrial gas turbine engine at steady state/transient, design/off-design and degraded state [24, 25].

Figure 5 also refers to a combustor emissions model developed at Cranfield University, named HEPHAESTUS. It is based on the stirred reactor concept [19. HEPHAESTUS accounts for different combustor geometries in terms of primary, intermediate and dilution zone volumes as well as the air mass flow distribution for a given combustor design. HEPHAESTUS has proven itself to be a reliable tool for rotorcraft studies [26].

Once the combustor model is sized and validated, it requires the atmospheric conditions (altitude, ambient temperature, and humidity), the combustor inlet conditions (total pressure, total temperature, and air mass flow) and the fuel flow as well as its temperature. HEPHAESTUS computes the emission index of the combustion products such as $\mathrm{CO}_{2}$ and $\mathrm{NO}_{x}$, which can then be integrated over the whole mission time frame to provide an estimation of the total environmental impact at mission level.

\subsection{Flight Path Definition}

In order to effectively simulate rotorcraft mission profiles, a 4-dimensional definition of the mission is required in terms of latitude, longitude, altitude and time. For that purpose, a flight path definition tool was developed and included in the rotorcraft performance simulation framework. This tool allows to define a complete mission through intermediate point coordinates under mission task elements such as idle, hover, level flight, etc. The flight path tool interpolates through the designated points following the procedure defined within each mission task element. Altogether, a high-fidelity mission profile is then generated. The flight path tool is based on the WGS84, providing translation between global geographical system (latitudelongitude) and the Cartesian level [20. The length in meters of a degree of latitude and longitude at latitude $x_{\text {lat }}$ is approximated by:

$$
d_{\text {lat }}\left(x_{\text {lat }}\right)=111132.954-559.822 \cos \left(2 x_{\text {lat }}\right)+1.175 \cos \left(4 x_{\text {lat }}\right)-0.0023 \cos \left(6 x_{\text {lat }}\right)
$$




$$
d_{\text {lon }}\left(x_{\text {lat }}\right)=111412.84 \cos \left(x_{\text {lat }}\right)-93.5 \cos \left(3 x_{\text {lat }}\right)+0.118 \cos \left(5 x_{\text {lat }}\right)
$$

$x_{l a t}$ is the latitudinal coordinate in degrees. $d_{\text {lat }}$ and $d_{\text {long }}$ are estimated at the sixth decimal accuracy. Those equations are utilised for the translation of coordinates from the global to the Cartesian system and vice versa.

\subsection{Integrated Mission Analysis}

The integrated mission analysis obeys the flowchart presented in Figure 4. Given a certain mission, the total fuel burn is first guessed by the user to set the initial $A U M$. The mission is then discretised with a predefined time step $\Delta t$. The rotorcraft is assumed to be flying at steady state, trim conditions along each segment. The engine is considered operating at steady-state off-design conditions along the whole mission.

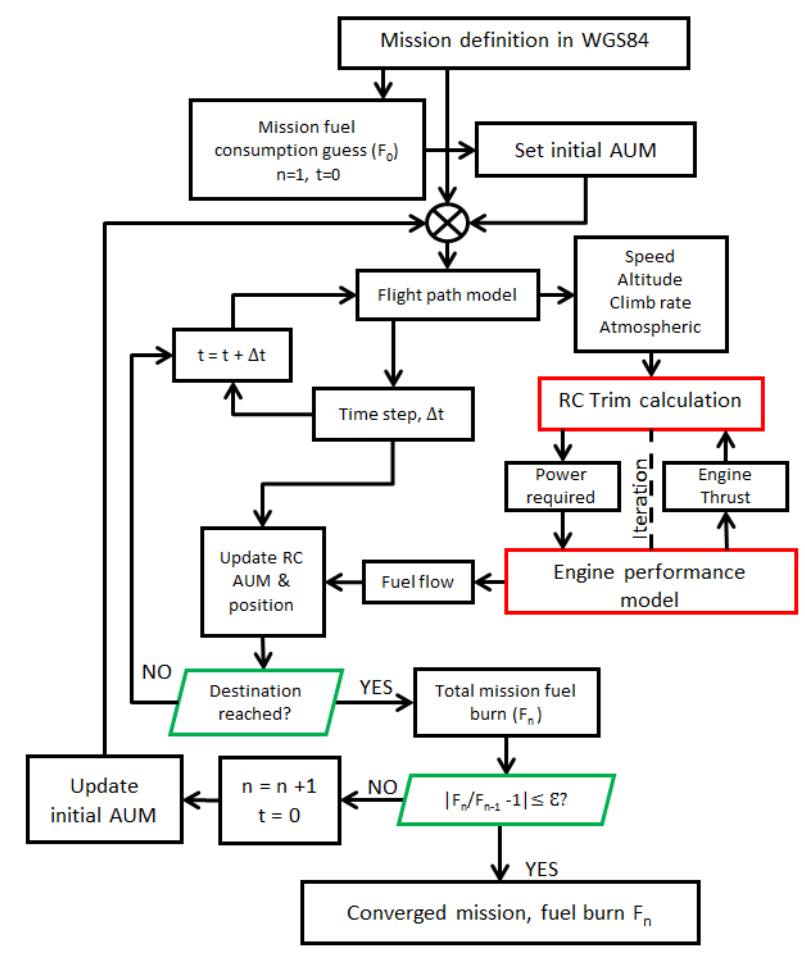

Figure 4: Integrated mission analysis in the rotorcraft simulation framework

The flight path routine provides the flight conditions (speed, altitude, climb rate, and atmospheric conditions) for a given segment. Trimming calculations are then carried out through an iterative process involving rotorcraft and engine models. The rotorcraft model provides the power required from the engine which, together with this power also generates a residual thrust that must be accounted for the trim calculations. Once the equilibrium is reached, the engine fuel flow determined by the engine model is then used to update the rotorcraft $A U M$. This method allows a real time rotorcraft weight estimation, capturing the gradual weight reduction during the mission as fuel is consumed.

The spatial position of the rotorcraft is also updated based on the flight conditions set for that segment by the flight path routine. The system executes this set of instructions iteratively until the destination is reached. At that point, the total mission fuel burn $\left(F_{n}\right)$ is estimated and is compared to the mission fuel burn originally guessed. If the error between the two quantities is above the error limit $\varepsilon$ set by the user, the system resets the rotorcraft AUM and repeats the whole process until the discrepancy between two successive iterations lies within the acceptable margin. With this method, the integrated framework is able 
to complete the simulation of a representative mission computing fuel burn, mission duration, and $N O_{x}$ emissions.

The complete platform is illustrated in Figure 5. It includes the aforementioned tools, their respective environment, and how the integration is realised. The platform allows the user to handle a large number of parameters from the rotorcraft itself to the combustor design, resulting in a versatile tool for the performance investigation of the rotorcraft architecture in realistic real-time applications.

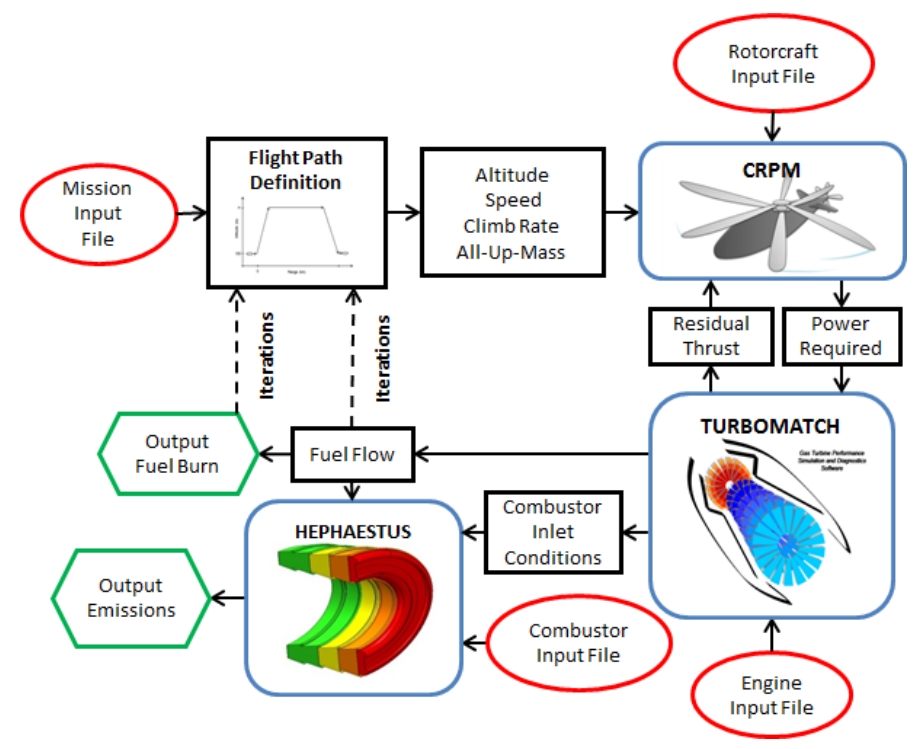

Figure 5: Multi-disciplinary rotorcraft performance model

\section{Verification of the Performance Model}

In order to gain confidence in the developed rotor model, the "rotor 1" of Harrington's experiments is modelled [27]. The rotor has two two-bladed untwisted coaxial rotors with a solidity of 0.054 , a rotor radius of $3.81 \mathrm{~m}$, and a rotor separation of $9.5 \%$ the rotor diameter. For modelling reasons, the blade section lift coefficient is assumed equals to $5.75 \alpha$ [27] and the profile drag coefficient is defined with the following function:

$$
c_{p 0}=\max (0.0124,0.49(1-\cos 2(\alpha+1.75))
$$

The profile drag coefficient taken from [28] which model the same rotor with an advanced Vorticity Transport Model (VTM). The calculated hover performances are plotted in Figure6(a) with the experimental data [27. and the performance calculated from the VTM [28. The calculated trend is within $10 \%$ of the experimental data, the highest errors appearing when no lift is generated. In order to evaluate the forward flight speed, the fuselage parasite drag is modelled with an equivalent plate area 0.02 times the rotor disk 28. The comparison between the VTM and calculated performance is plotted in Figure 6(b) The error remains below $3 \%$ for advance ratios above 0.14 . The calculated rotor inputs trends are similar to one estimated with the VTM with errors under $15 \%$.

The second level of verification is realised with the flight test data from the Sikorsky X2TD available in [9]. The main characteristics of this rotorcraft are summarised in Table 1. Some further details can be found in [13, 29].

Bagai 13 gives a detailed description of the coaxial rotor characteristics, i.e. chord, twist, thickness and some details about the airfoils used. This was used as a guidance to set the coaxial rotor characteristics. Three airfoils are used to characterise the rotor blade. The blade root is defined with the DBLN526, a 


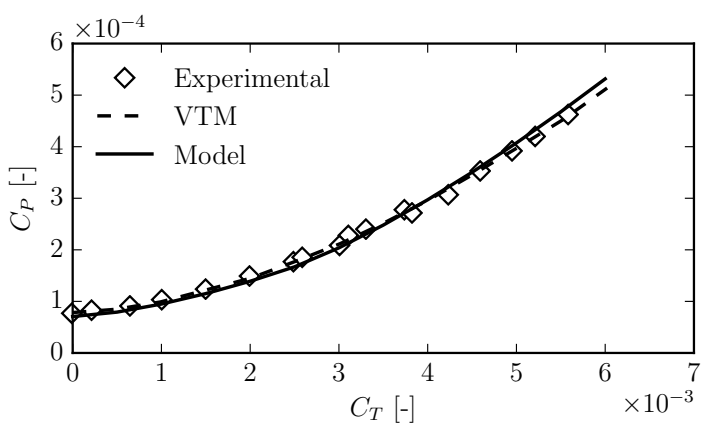

(a)

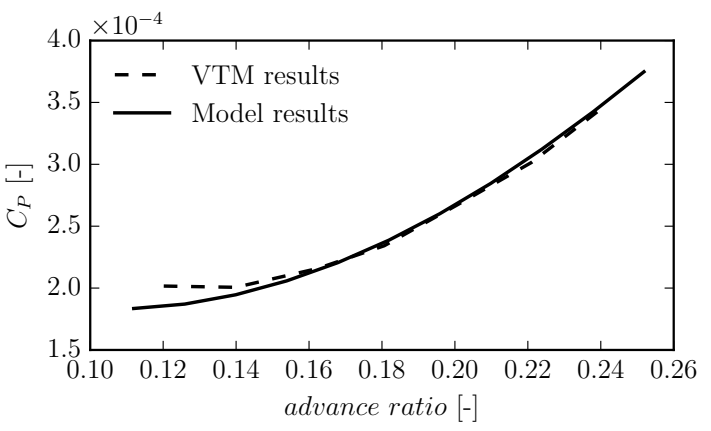

(b)

Figure 6: Performance of the Harrington's "rotor 1" at hover (a) and forward flight (b)

Table 1: Characteristics of the Sikorsky X2TD rotorcraft

\begin{tabular}{ll}
\hline Attribute & X2TD \\
\hline \hline MTOW & $2721 \mathrm{~kg}$ \\
Rotor diameter & $8.05 \mathrm{~m}$ \\
Rotor configuration & 2 four-bladed coaxial rotors \\
Propeller diameter & $2.14 \mathrm{~m}$ \\
Propeller configuration & 1 six-bladed pusher propeller \\
Powerplant & 1 T800-LHT-801 (918kW @ continuous power) \\
\hline
\end{tabular}

double-ended airfoil. The middle of the blade is defined by the Sikorsky SC1012R8 airfoil whilst a Sikorsky transonic airfoil, the SSC-A09, is chosen at the blade tip. The aerodynamic characteristics of these blades are saved in look-up table. Linear interpolation is used for the smooth transition between each airfoil.

The flapping motion of the rotor blade is estimated with the centre spring equivalent rotor. The blade stiffness is characterised thanks to the first flap model harmonic of the rotor blade (1.4 per revolution) 9 . The blade inertia must be specified. The flap motion can be subsequently verified with the calculation of the tip clearance during level flight.

The airframe, rotor hubs and shaft, and the wings are characterised by polar curves. At $100 \mathrm{~m} / \mathrm{s}$, the rotor hubs and shaft drag represents $46 \%$ of the overall aircraft drag excluding the rotor drag. The wing lift and the total aircraft drag are calculated and compared with Johnson's model [15] detailed in [30 as illustrated in Figure 7. Wing lift and aircraft drag are similar for the two models. The wings provide a significant amount of lift, representing up to $30 \%$ of the vehicle MTOW at $120 \mathrm{~m} / \mathrm{s}$.

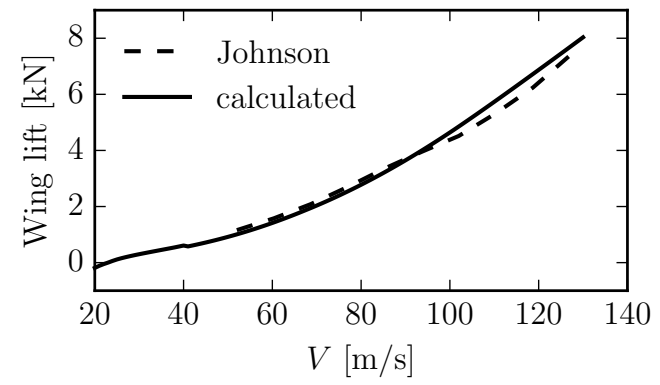

(a)

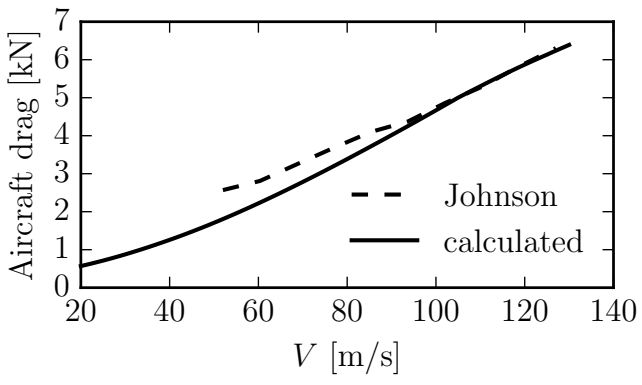

(b)

Figure 7: Calculated aircraft lift (a) and drag (b), vs. Johnson's model 30 
A set of assumptions was underlined in the section describing the rotorcraft performance model, in order to numerically solve the trim state of the rotorcraft system. The first one refers to the coaxial rotor longitudinal moment. The longitudinal cyclic input $\theta_{1 C}$ is identical for both rotors. The second assumption allows the control of the lift-offset capability of the coaxial rotor, which can be quantified thanks to the rolling moment $\left(M_{\text {roll }}\right)$ of both rotors of the counter-rotating rotor system. The lift-offset can be expressed as:

$$
L_{\text {offset }}=\frac{M_{\text {roll }}}{0.5 R_{\text {rotor }} A U M}
$$

which is the ratio between the actual rolling moment and a fictional case where the totality of the rotor lift is produced at the rotor tip at 90 degrees azimuth. The lift is represented by $A U M / 2$, giving an even separation between the two coaxial rotors.

The Mach number distribution over the rotor disk shown in Figure 8 underlines the environment in which lift has to be generated by the rotor. The rotor speed is limited in order to keep the rotor tip of the advancing side below Mach 0.9. It appears that at the given speed ( $\mathrm{V}=120 \mathrm{~m} / \mathrm{s}$ ), the reverse flow region represents a large section on the retreating side, extended up to $65 \%$ of the blade. Therefore, little lift can be generated in this area. Simultaneously, lift is easily generated on the advancing side.

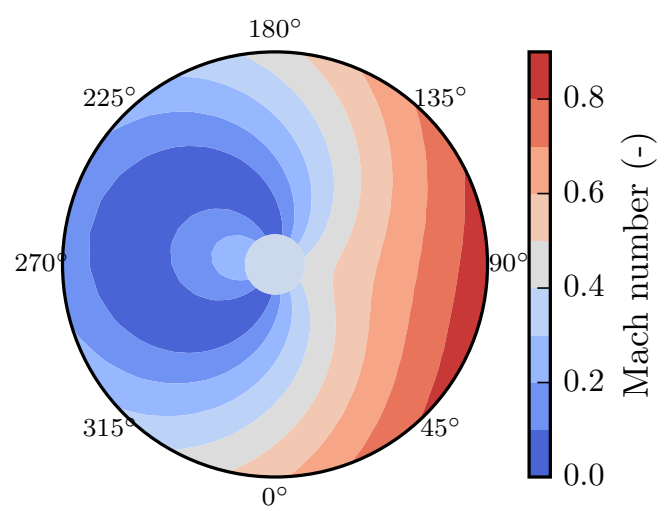

Figure 8: Mach number distribution at $\mathrm{V}=120 \mathrm{~m} / \mathrm{s}$

Figure 9 highlights the lift distribution over the rotor disk for two $L_{\text {offset }}, 0$ and $50 \%$. For $L_{\text {offset }}=$ $0 \%$, the lift is produced principally over two regions, namely the first and last quarter of the rotor advancing side, while the tip region at azimuth 90 degrees is negatively loaded. At $L_{\text {offset }}=50 \%$, the two regions join together to form a unique area. The negatively loaded region is also weakened. The regions generating the most lift has moved further on the advancing side as $L_{\text {offset }}$ increases. This is coherent with Bagai's simulations [13.

Walsh et al. 9] provide the lateral lift-offset achieved during fight testing of the X2TD. The lift-offset appears to gradually increase as the speed increases. Besides, there is little interest to have lift-offset at hover therefore, $L_{\text {offset }}$ is defined as a linear function of the forward speed resulting in the following description of $M_{\text {roll }}$

$$
M_{\text {roll }}=K_{\text {roll }} L_{o f f s e t}^{100} V R_{\text {rotor }} A U M
$$

Where $L_{\text {offset }}^{100}$ is the lift-offset at $\mathrm{V}=100 \mathrm{~m} / \mathrm{s}$ in percentage. $L_{\text {offset }}^{100}$ is chosen in order to correlate the flight test data of the modelled aircraft. Figure 10 displays the comparison between the X2TD flight test data and the followed equation for several $L_{\text {off set }}^{100}$. Although the model is rather simplistic, the lift-offset trend is well catered with $L_{o f f s e t}^{100}=15 \%$.

Simultaneously, the rotorcraft pitch attitude, $\alpha_{\text {airframe }}$ has a significant impact on the power split between the rotor and the propeller. $\alpha_{\text {airframe }}$ can be chosen thanks to the presence of an auxiliary propulsion 


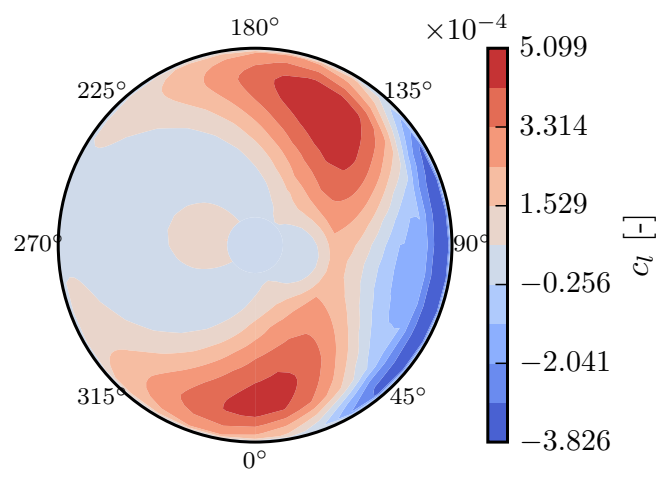

(a) $L_{\text {offset }}=0 \%$

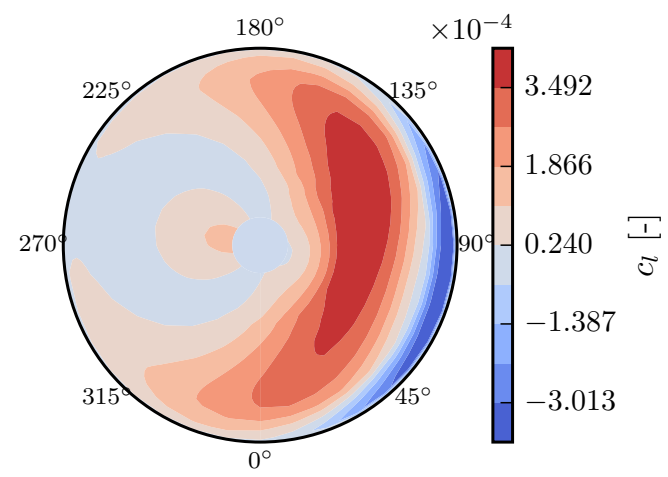

(b) $L_{\text {offset }}=50 \%$

Figure 9: Lift distribution of the X2TD rotor disk for $\alpha_{\text {airframe }}=0^{\circ}$ at $V=120 \mathrm{~m} / \mathrm{s}$

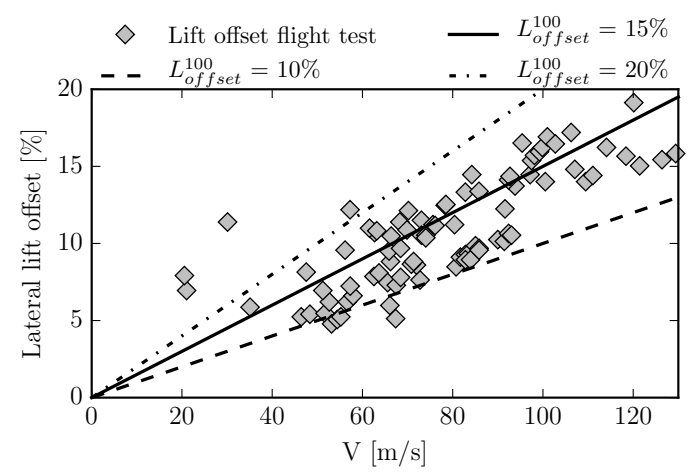

Figure 10: lift-offset, X2TD flight test data [9] versus model different $L_{\text {off }}^{100}$ set

system. The main rotor produces lift, whilst the propulsive force is provided by the rear-mounted propeller. Figure 11 highlights $\alpha_{\text {airframe }}$ impact on the rotorcraft performance. $P_{\text {total }}$ and the ratio $P_{\text {rotor }} / P_{\text {total }}$ are plotted as a function of $\alpha_{\text {airframe }}$ and $V$. The altitude $(H), A U M$, and the climb rate $\left(V_{C}\right)$ have also a significant effect on the overall performance and power share for a given $\alpha_{\text {airframe }}$.

At hover condition, $\alpha_{\text {airframe }}$ has a relativity small impact on $P_{\text {total }}$ (Figure 11(a)p. This is interesting in the case of take-off/landing in dirty environments where the risk of brownout is important. Indeed, the rotorcraft can hover with a negative $\alpha_{\text {airframe }}$ pushing the dust away from the rotorcraft, potentially leaving clear visibility for the pilot and clean air at the engine intake [31. Similarly, the vehicle eliminates flare to hover 31.

Looking at the study as a whole (Figure 11), the main highlight is the possibility to fly the rotorcraft under different $\alpha_{\text {airframe }}$ at any given condition. The minimum $P_{\text {total }}$ is found where the ratio $P_{\text {rotor }} / P_{\text {total }}$ is close to $25 \%$ when $V=100 \mathrm{~m} / \mathrm{s}$. According to Figure 11 , in order to keep $P_{\text {total }}$ to a minimum, the ratio $P_{\text {rotor }} / P_{\text {total }}$ reduces with speed (approximately $15 \%$ at $V=120 \mathrm{~m} / \mathrm{s}$ ). This is a trade off between high parasitic drag and high induced and profile drag. The X2TD is flown with the rotor in an autorotation state with a positive pitch attitude varying from 2 to 5 degrees for speeds above $60 \mathrm{~m} / \mathrm{s}$ [9. Consequently, $\alpha_{\text {airframe }}$ must be restrained bearing in mind the impact the flight conditions (i.e. flight speed, climb rate, altitude, and $A U M)$ have on $\alpha_{\text {airframe }} . \alpha_{\text {airframe }}$ is defined by the following expression:

$$
\alpha_{\text {airframe }}=\alpha_{\text {airframe }}^{H, M}(V, A U M, H)+\alpha_{\text {airframe }}^{C}\left(V, V_{C}\right)
$$

Where, $\alpha_{\text {airframe }}^{H, M}$ accounts for the effect of rotorcraft mass and flight altitude and $\alpha_{\text {airframe }}^{C}$ tackles the 


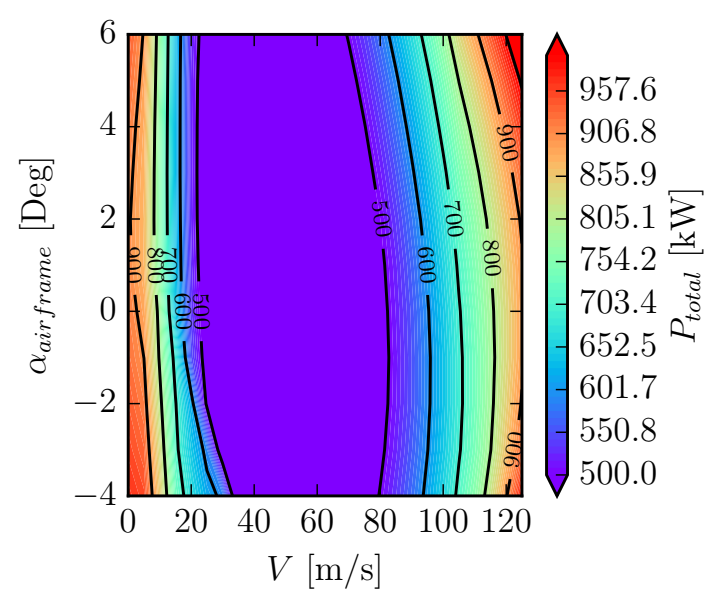

(a) $P_{\text {total }}$ vs. $V$

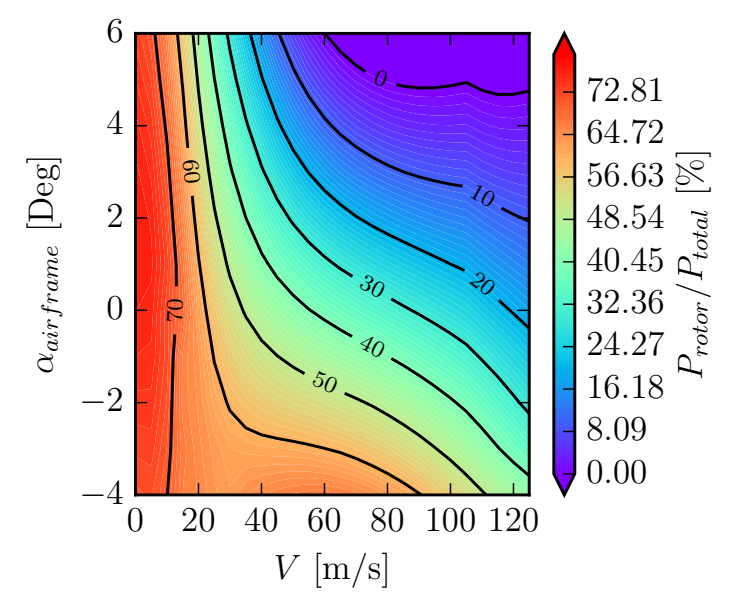

(b) $P_{\text {rotor }} / P_{\text {total }}$ vs. $V$

Figure 11: Study of the impact of $\alpha_{\text {airframe }}$ on rotorcraft total power, $P_{\text {total }}$, and power shared $P_{\text {rotor }} / P_{\text {total }}$

impact of the climb rate. $\alpha_{\text {airframe }}^{H, M}$ is based on a $2 \mathrm{D}$ interpolation established with the data generated during the study. $\alpha_{\text {airframe }}^{C}$,on the other hand, is defined hereafter:

$$
\alpha_{\text {airframe }}^{C}\left(V, V_{C}\right)=k V^{n} \tan ^{-1} \frac{V_{C}}{V}
$$

Once $\alpha_{\text {airframe }}$ is specified for any flight condition, the performance of the rotorcraft model is calculated and compared with the flight test data from the Sikorsky X2TD (Figure 12(a)). The shape of the overall rotorcraft power is a classic "bucket-shape" curve characteristic of conventional helicopters. At lower speeds, the power demand is driven by the induced power term. At high speeds, the parasite power becomes the dominant term. The specificity of the rotorcraft architecture is the separation of the induced and parasite power between the rotor and the propeller, $P_{\text {rotor }}$ and $P_{\text {prop }}$ being comparable to the induced and parasite power, respectively. This results in the $P_{\text {rotor }}$ and $P_{\text {prop }}$ curves in Figure 12(a) $P_{\text {rotor }}$ is inversely proportional to the vehicle speed, whereas $P_{\text {prop }}$ is proportional to the square of velocity. The rotor is actually in a autorotating state at high speeds in order to accurately mimic the X2TD. This rotor state is achieved with a careful choice of rotorcraft pitch attitude governing the power split between the rotating systems as previously highlighted. Figure $12(\mathrm{~b})$ shows the law followed for $\alpha_{\text {airframe }}$ in order to provide performance curves resembling the X2TD flight test data trends. $\alpha_{\text {airframe }}$ gradually increases from approximately zero degrees to plateau above $100 \mathrm{~m} / \mathrm{s}$ at 4.5 degrees. This is similar to the observations made during the X2TD flight tests where the rotorcraft flew at pitch attitude from 2-5 degrees above 60 $\mathrm{m} / \mathrm{s}$. This choice of $\alpha_{\text {airframe }}$ does not appear to be "optimum" for minimum power. The calculated $P_{\text {total }}$ appears to reach a minimum for $\alpha_{\text {airframe }}$ closes the 0-1 degrees as illustrated by Figure 11(a).

The calculated flight control inputs are shown in Figure 13 . The $\theta_{0}$ trend is to correlate with $P_{\text {rotor }}$ 's one. $\theta_{1 s}$ depends directly on $L_{o f f s e t}$, increasing with speed. $\theta_{1 C}$ hits a maximum at about $20 \mathrm{~m} / \mathrm{s}$. This is mainly the result of longitudinal trimming. Delta in the collective $\left(\Delta \theta_{0}\right)$ and lateral cyclic $\left(\Delta \theta_{1 S}\right)$ appear at low and high speeds, resulting from the interactions between the two rotors. The rotorcraft model noses up as speed increases as seen in Figure 12(b). This derives into variation of the wake skew angle $(\chi)$, thus the corrections $\Gamma^{U L}$ and $\Gamma^{L U}$ increases, resulting in an inflow delta of approximately $0.5 \%$ between the two rotors. Moreover, the divergence is amplified as the lift-offset increases. The change in slopes at $100 \mathrm{~m} / \mathrm{s}$ in several plots is due to the rotational speed schedule to limit the rotors' advancing blade Mach number. The propeller collective pitch is also calculated, gradually increasing from -19 to 42 degrees representative of $P_{\text {prop }}$ variations.

The rotorcraft performance is also summarised in Figure 14 where $L / D=V W / P$ is calculated and 


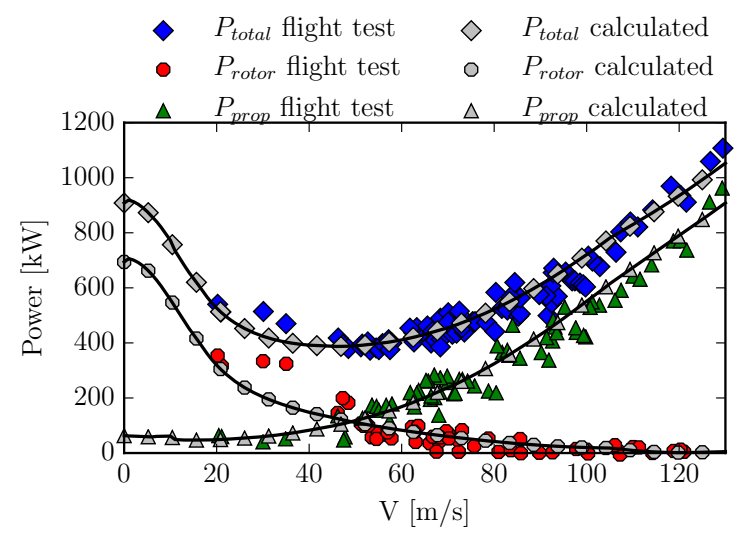

(a)

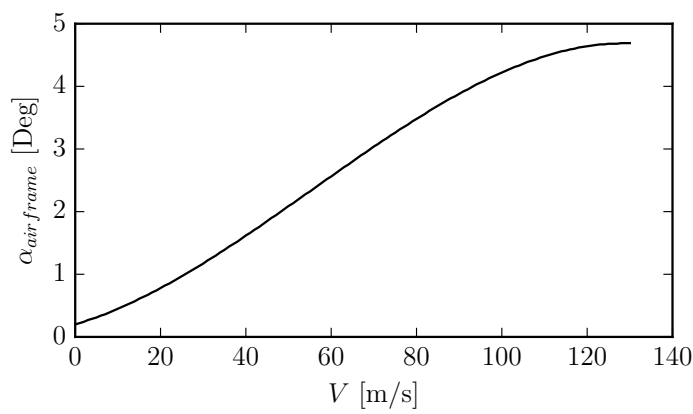

(b)

Figure 12: (a) Performance of the rotorcraft model compared to the flight test data 9, with the calculated $\alpha_{\text {airframe }}$
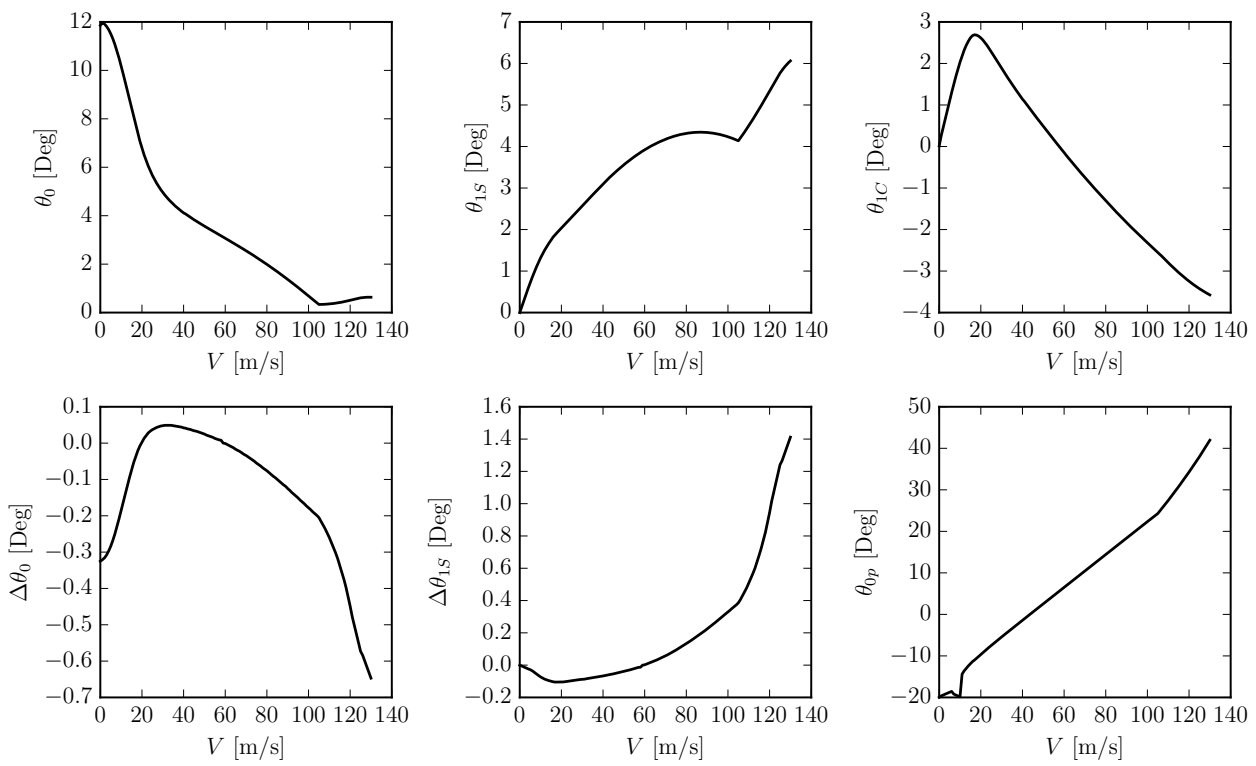

Figure 13: Calculated control inputs

compared with Johnson's model. The rotor efficiency, defined as $L / D e$, is also calculated:

$$
L / D e=\frac{L_{\text {rotor }}}{D_{\text {rotor }}+\frac{P_{\text {rotor }}}{V}}
$$

where $L_{\text {rotor }}, D_{\text {rotor }}$, and $P_{\text {rotor }}$ are the overall coaxial rotors lift, drag, and power, respectively. $L / D e$ provides a measure of rotor efficiency in forward flight specifically. Both models are similar with a maximum $L / D$ reaching 4.3 and 4.1 for the Johnson's and the current model, respectively, at approximatively same speed (around $75 \mathrm{~m} / \mathrm{s}$ ). L/De calculated by both models are also similar. $L / D e$ values calculated herein hits a maximum at $70 \mathrm{~m} / \mathrm{s}$ whilst Johnson's rotor maximum is reached at $85 \mathrm{~m} / \mathrm{s}$ at about 10 . The effect of rotor speed schedule is apparent for both models, at $V=110$ and $120 \mathrm{~m} / \mathrm{s}$, respectively. The coaxial rotor tip separation is also calculated and compared with the flight test data (Figure 15). Although the flapping model is simple, the general trend is well catered for a blade inertia of $250 \mathrm{~kg} . \mathrm{m}^{2}$. 


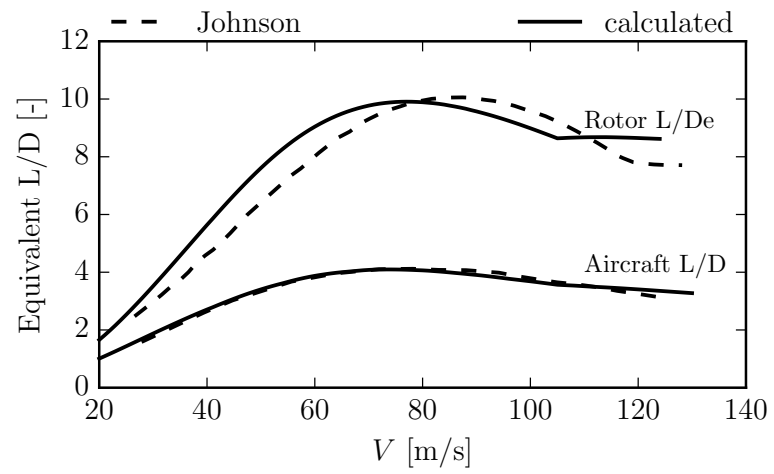

Figure 14: Rotorcraft and rotor efficiency

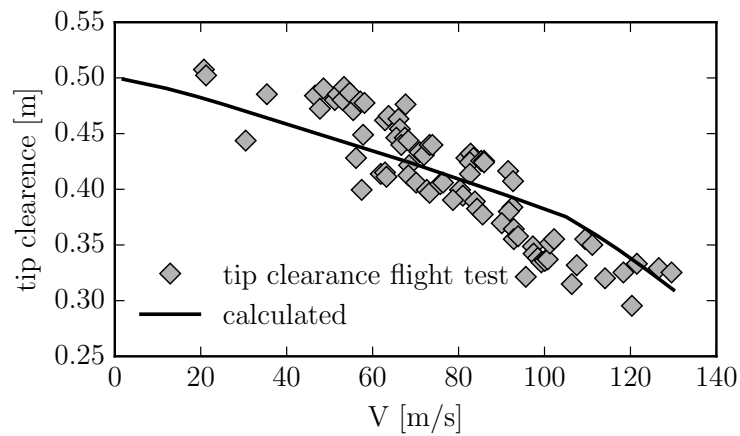

Figure 15: Tip clearance, $X 2^{T D}$ flight test data 9] versus model

This completes the verification of the rotorcraft performance simulation code. Accurate predictions of the Harrington's "rotor 1" and the Sikorsky X2TD performance are acquired, bringing confidence for future applications of the tool.

\section{Case Study}

\subsection{Overview}

The rotorcraft architecture modelled does not currently exist in the civil market. However, the growing demand for fast rotorcraft will certainly result in the appearance of similar architectures. The performance and the environmental impact assessment of the aforementioned technology are necessitated in order to successfully integrate fast rotorcraft in the global air traffic. Passenger transport/air taxi operations are expected to boom in the near future. Therefore a conceptual rotorcraft is modelled for such applications. Its general characteristics are given in Table 2, which are similar to the Sikorsky X2TD ones. The rotor airfoil distribution is thus maintained between the two vehicles. For the present study, $L_{o f f s e t}^{100}$ is kept at $15 \%$, whilst $\alpha_{\text {airframe }}^{H, M}$ is set to zero independently of the conditions. The blade inertia determined for the $X 2 T D$ is also conserved.

Johnson [15] attempted to account for the effect of lift-offset on rotor hub and blade weight and thus overall rotorcraft mass. The several cases of conceptual civil rotorcraft reach $58 \% \mathrm{EW} / \mathrm{MTOW}$ on average for $20 \%$ lift-offset. A conservative value of $60 \% \mathrm{EW} / \mathrm{MTOW}$ ratio is used herein.

The general performance of the concept is calculated and summarised in Figure 16. The general power curve trend is similar to the X2TD "bucket-shape" one. The rotor and propeller have also similar behaviours 
Table 2: Main characteristics of the conceptual rotorcraft model

\begin{tabular}{ll}
\hline Attribute & Concept \\
\hline \hline MTOW & $3000 \mathrm{~kg}$ \\
EW/MTOW & $60 \%$ \\
Rotor diameter & $8.4 \mathrm{~m}$ \\
Rotor configuration & 2 four-bladed coaxial rotors \\
Propeller diameter & $2.14 \mathrm{~m}$ \\
Propeller configuration & 1 six-bladed pusher propeller \\
Powerplant & 1 T700-GE-700 $(1,210 \mathrm{~kW} @$ intermediate rating $)$ \\
\hline
\end{tabular}

as the ones illustrated in Figure $12(\mathrm{a})$, where the rotor and propeller are representative of the induced and parasite power, respectively. The effects of altitude and AUM (or payload) are also highlighted in Figure 16. At a given altitude, the impact of payload on the power is seen at hover and low speed, whilst very little effect is seen at high speeds. The hover increases by approximately $4 \%$ per $100 \mathrm{~kg}$ in comparison with AUM $=$ MTOW. On the other hand, the altitude plays an important role at high speeds. On average, a $7 \%$ drop per $1000 \mathrm{~m}$ in power is calculated at $110 \mathrm{~m} / \mathrm{s}$, whilst the hover power increases by $3 \%$ per $1000 \mathrm{~m}$. This is compared to sea level performances. The previous discussion highlights the relative impact of payload and altitude on induced and parasite power. Payload drives the induced power leading to the effects at low speeds. Altitude influences both induced and parasite powers. Indeed, induced power is proportional to density, whilst parasite power is inversely proportional to it [21].

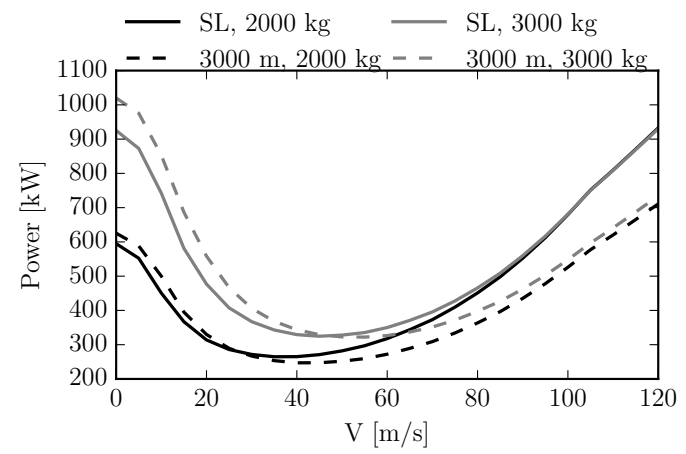

Figure 16: Calculated power required for the conceptual rotorcraft

The rotorcraft powerplant employed in the analysis is a General Electric T700-GE-700 turboshaft engine. The choice of this particular engine was motivated by the fact that it belongs to the same power level category as the T800-LHT-801 engine and its off-design performance is widely documented and simulated in 32. In this reference, some steady-state performance maps created by the engine manufacturer simulation software called GE status-81 are collected. The comparison of these results with the ones produced by the model created in TURBOMATCH for this engine is shown in Figures 17(a) 17(b), The combustor of the T700-GE-700 engine was also modelled in HEPHAESTUS and its $N O_{x}$ prediction accuracy verified against experimental data [33, 34. The results of this validation process are shown in Figure 17(c), The engine/combustor model created appears sufficiently accurate to effectively simulate the performance of the T700-GE-700 engine throughout the whole rotorcraft operating range.

As previously mentioned, the modelled rotorcraft has a coaxial rotor with a pusher propeller architecture. Such designs are expected to fly at greater cruise speed and altitude than conventional rotorcraft. Therefore, the following analysis aims to assess the impact of cruise speed and altitude on mission duration, fuel burn, and $N O_{x}$ emissions. As mentioned in the introduction, inter-city passenger transport/taxi VIP operations are expected to rise sharply in the near future. They are generally modelled as a number of legs including 


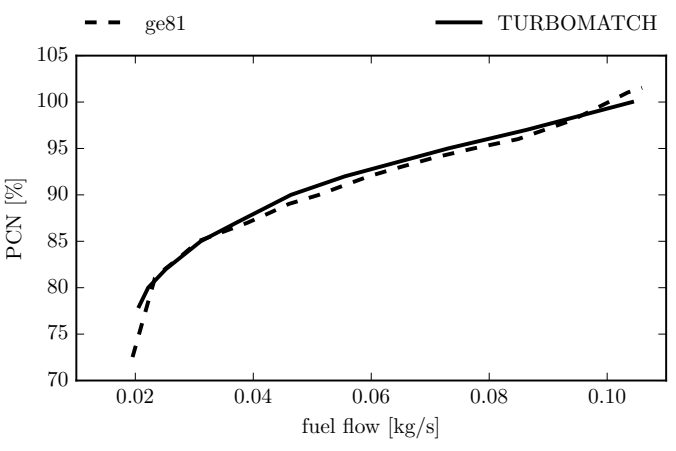

(a)

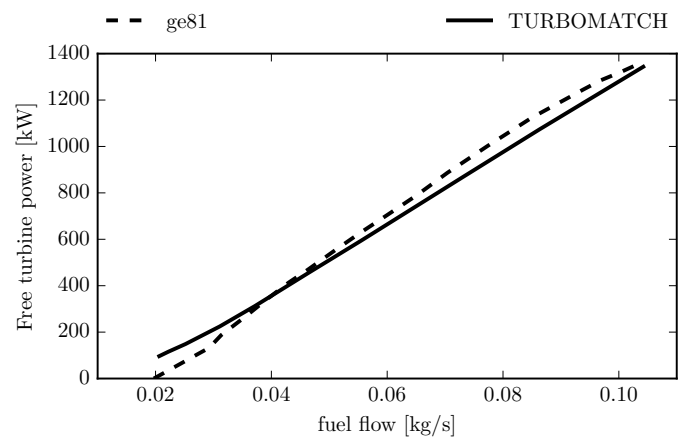

(b)

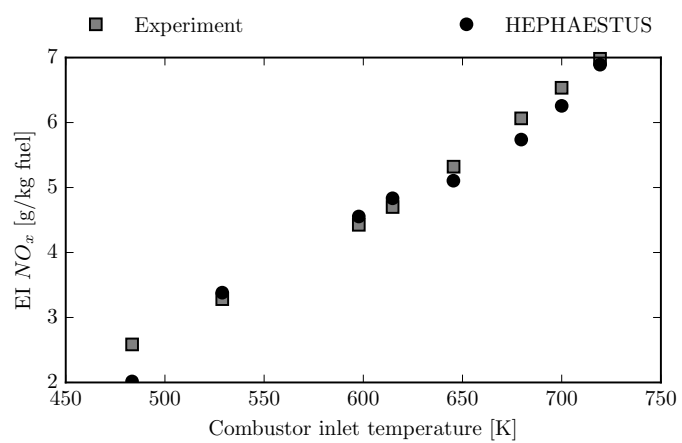

(c)

Figure 17: Validation of the T700 engine model. (a) gas generator speed, (b) Free turbine power vs engine fuel flow [32](c) $N O_{x}$ emission index vs combustor inlet temperature

take-off, climb, cruise, descent, and landing in a relatively straight trajectory when noise emissions are not accounted for [16. Indeed this is the shortest path between two points resulting in the lowest mission fuel burn. Therefore, a single leg is considered in the study. The conclusions can be subsequently applied to multiple legs missions. A $100 \mathrm{~km}$ long scenario is chosen. The payload breakdown is enumerated in Table 3.

\begin{tabular}{ll} 
Table 3: Mission payload breakdown \\
\hline Number of Passengers & 6 \\
Passenger Mass & $90 \mathrm{~kg}$ \\
Luggage Mass & $25 \mathrm{~kg}$ \\
Total Useful Payload & $690 \mathrm{~kg}$ \\
\hline
\end{tabular}

The mission's details are given in Figure 18 , where $V$ and $H$ are the cruise speed and altitude, respectively. The take-off occurs at an altitude of $100 \mathrm{~m}$, whilst the landing is set at sea level. A time step $\Delta t$ of 15 seconds is used. to provide a trade-off between fidelity and computational time.

The parametric study is limited to the impact of cruise speed and altitude with regard to mission duration, fuel burn, and $N O_{x}$ emissions. The bounds set are provided in Table 4 . Once a pair $H, V$ is chosen, the coordinates of the point $\mathrm{B}$ are calculated. This is where the descent must start in order to reach the landing point in the specified conditions. As for the point A, although its position changes with the cruise altitude, it is not needed for the mission definition input. This completes the definition of the mission for a pair $(H, V)$. The rotorcraft emissions are subsequently evaluated. 


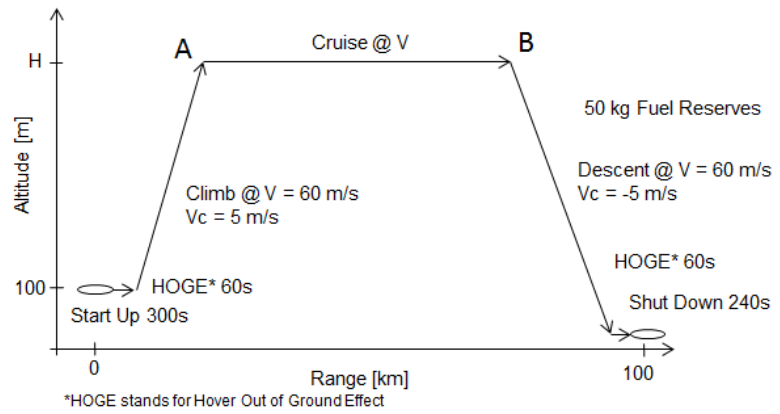

Figure 18: General mission design

Table 4: Design space bounds for mission parametric study

\begin{tabular}{cccc}
\hline & Lower bound & Upper bound & Units \\
\hline \hline$V$ & 60 & 120 & $\mathrm{~m} / \mathrm{s}$ \\
$H$ & 400 & 3000 & $\mathrm{~m}$ \\
\hline
\end{tabular}

\subsection{Results}

The results of the study are summarised in Figure 19 where mission duration $\left(t_{\text {mission }}\right)$, fuel burn $\left(m_{\text {fuel }}\right)$, and $N O_{x}$ emissions $\left(m_{N O_{x}}\right)$ are plotted with respect to cruise conditions $(V$ and $H)$.

Unsurprisingly, $t_{\text {mission }}$ decreases with an increase in cruise speed, but increases with altitude (Figure 19(a)], as the vehicle spends more time on the climb and descent segments. Figure 19(b) exhibits the relative influence of $V$ and $H$ with regards to $m_{f u e l}$. The minimum calculated $m_{\text {fuel }}$ is at $V=90 \mathrm{~m} / \mathrm{s}$ and $H=$ $2711 \mathrm{~m}$. Similarly, $m_{N O_{x}}$ variations are illustrated in Figure 19(c), A "optimum" scenario is calculated at $V=80 \mathrm{~m} / \mathrm{s}$ and $H=3000 \mathrm{~m}$.

The speed resulting into minimum $m_{f u e l}$ is the best range speed. The speed is graphically highlighted in Figure 20. Mathematically, the best range speed minimises the ratio $w_{f}$ over $V$ to get the trade-off between high speed and low consumption. At AUM $=2700 \mathrm{~kg}$ the best range speed increases from $85 \mathrm{~m} / \mathrm{s}$ at sea level to approximately $90 \mathrm{~m} / \mathrm{s}$ at $3000 \mathrm{~m}$. The engine fuel flow also greatly reduces with altitude as density and thus parasite power reduces. This results in a $8.0 \% w_{f}$ reduction per 1000 meters at $90 \mathrm{~m} / \mathrm{s}$ in comparison with the sea level estimate. Therefore, the minimum $m_{\text {fuel }}$ should be found at the highest altitude but this does not take into account the climb and descent segments which play a role at mission level.

As for the minimum $m_{N O_{x}}$, a similar discussion can be realised. From Figure 21, the best $w_{N O_{x}}$ speed increases from $70 \mathrm{~m} / \mathrm{s}$ at sea level to $80 \mathrm{~m} / \mathrm{s}$ at $3000 \mathrm{~m}$. However, an average $8.2 \% w_{N O_{x}}$ decrease per 1000 $\mathrm{m}$ is calculated at $80 \mathrm{~m} / \mathrm{s}$. The mission with minimum $m_{N O_{x}}$ is then a trade-off between the low $N O_{x}$ emission at high altitude and the time spent at cruise.

Table 5 presents three selected missions which can be presented as minimum $t_{\text {mission }}$, minimum $m_{\text {fuel }}$, and minimum $m_{N O_{x}}$ among the calculated $100 \mathrm{~km}$ scenarios. Environmental friendly scenarios are found at relatively high altitude, around $2667 \mathrm{~km}$ for the selected mission length, whilst fast missions are completed at low altitude and high speed (Case C). As previously mentioned, the presence of an optimum cruise speed for low $N O_{x}$ is highlighted (Case A). The minimum $m_{\text {fuel }}$ (Case B) is found in between the two cases, with a cruise speed of $90 \mathrm{~m} / \mathrm{s}$ at an altitude of $2711 \mathrm{~m}$.

Case A and B presents similar results, therefore only case A and C are considered in the following discussion. Case A represents an environmental friendly scenario, whilst case $\mathrm{C}$ represents a fast scenario. Their respective mission profiles are plotted in Figure 22. Due to the high cruise altitude, the climb and descent segments represent a large party of the scenario A whilst the low cruise altitude of the case $\mathrm{C}$ leads to short climb and descent.

Engine fuel flow and $N O_{x}$ rate are plotted in Figure 23, $w_{f}$ and $w_{N O_{x}}$ are high during take-off and landing, being up to twice the rates at any other segments for the scenario A. On scenario $\mathrm{C}, w_{f}$ and $w_{N O_{x}}$ 


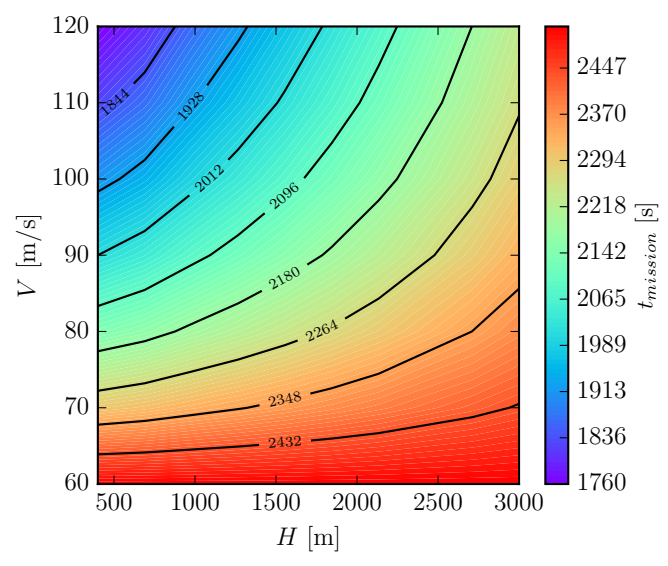

(a) $t_{\text {mission }}$

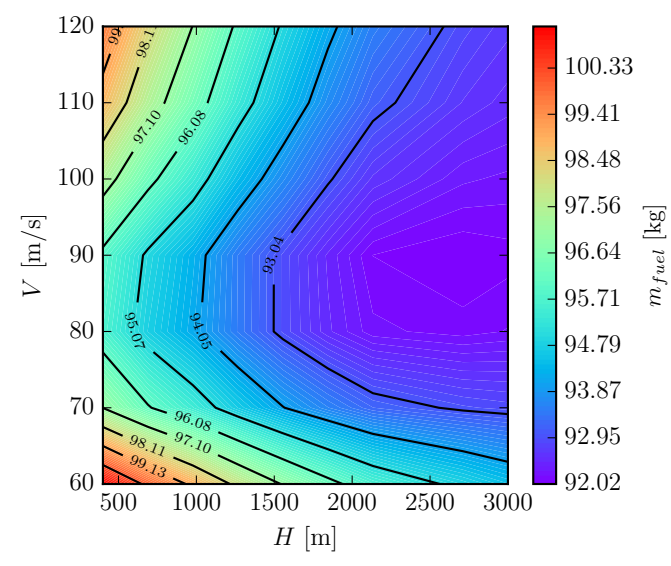

(b) $m_{\text {fuel }}$

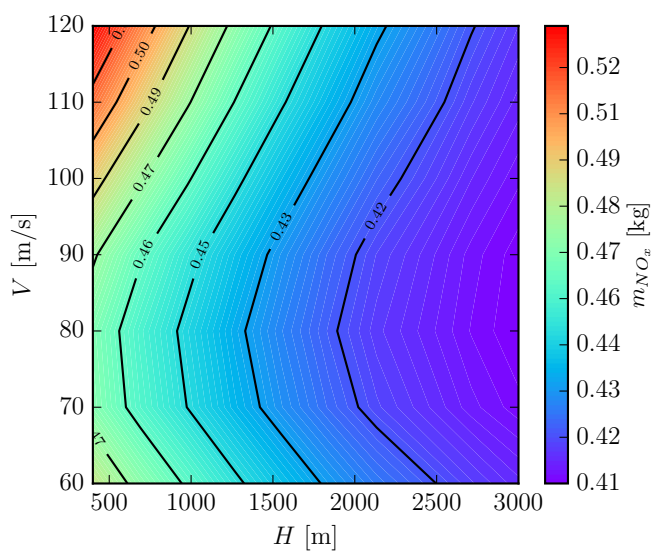

(c) $m_{N O_{x}}$

Figure 19: Impact of cruise speed $V$ and cruise altitude $H$ on (a) mission duration, (b) fuel burn, (c) $N O_{x}$ emissions

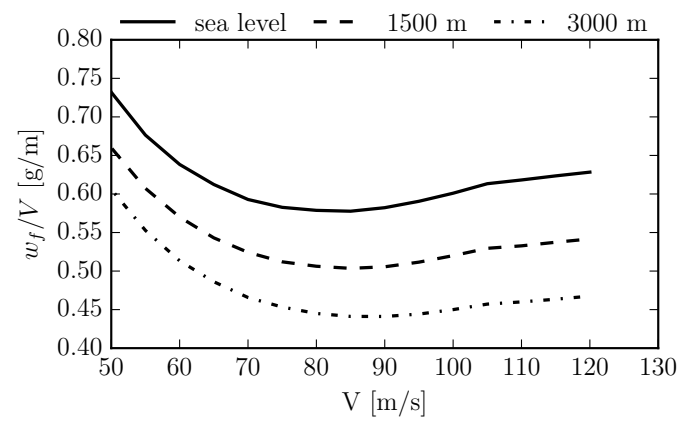

Figure 20: Ratio $w_{f} / V$ versus forward speed and altitude at ISA conditions and AUM $=2700 \mathrm{~kg}$

hits their maximum during the cruise segment. The cruise $w_{f}$ and $w_{N O_{x}}$ are 1.78 and 2.63 times higher on scenario C compared with scenario A, respectively. This is due to both cruise altitude and speed beneficial impact on engine power (see Figure 16) and combustion conditions. Figure 24 shows the effect of speed and 


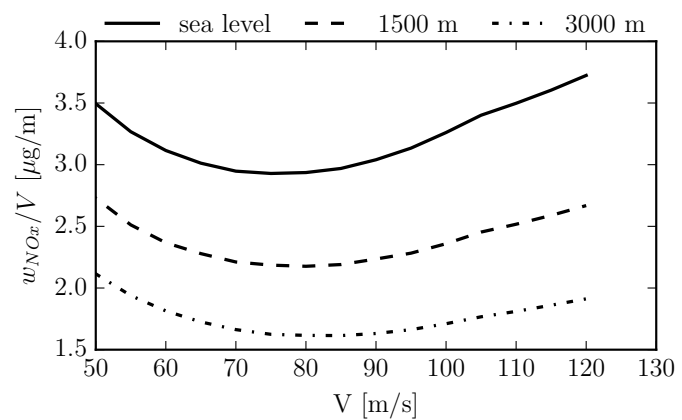

Figure 21: Ratio $w_{N O_{x}} / V$ versus forward speed and altitude at ISA conditions and AUM $=2700 \mathrm{~kg}$

\begin{tabular}{lcccc}
\multicolumn{5}{c}{ Table 5: The selected cases characteristics and their results } \\
\hline & & Case A & Case B & Case C \\
& Units & Fuel min & $N O_{x}$ min & Time min \\
\hline \hline$V$ & $\mathrm{~m} / \mathrm{s}$ & 90 & 80 & 120 \\
$H$ & $\mathrm{~m}$ & 2711 & 3000 & 400 \\
\hline$t_{\text {mission }}$ & $\mathrm{s}$ & 2291 & 2374 & 1760 \\
$m_{\text {fuel }}$ & $\mathrm{kg}$ & 92.0 & 92.2 & 99.7 \\
$m_{N O_{x}}$ & $\mathrm{~kg}$ & 0.409 & 0.405 & 0.523 \\
\hline
\end{tabular}

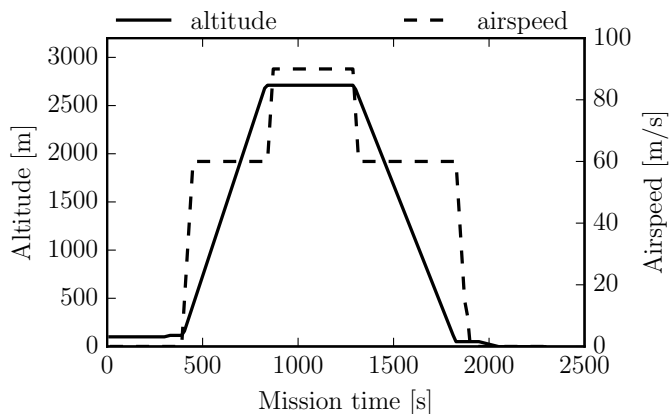

(a) Case A

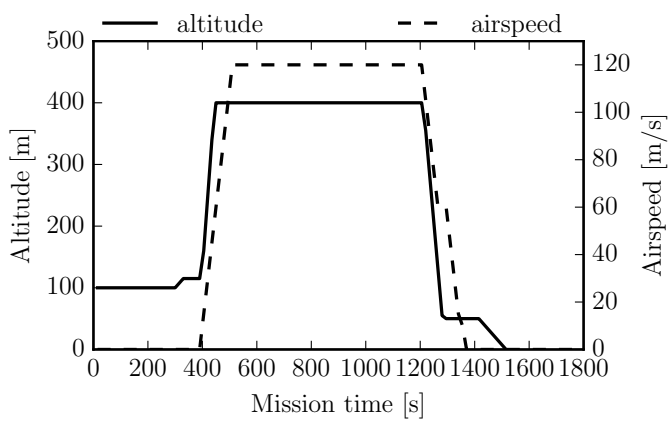

(b) Case C

Figure 22: Altitude and airspeed variation with mission time for scenario A (a) and C (b)

altitude on both $w_{f}$ and $w_{N O_{x}}$. Flying at high altitude reduces drastically the emissions at high speeds. This also explains the trend Figure 19 where high cruise altitude is genuinely favourable for low emissions.

A second parametric study was carried out on a mission over a $300 \mathrm{~km}$ range. The cruise altitude becomes the key parameter in this case. The minimum fuel burn is achieved at high altitude, where the upper bound is hit. The previously established "optimum" speeds remain unchanged.

\section{Conclusion \& Future Work}

The objective of this work was to set the basis for a method to thoroughly evaluate the performance of conceptual coaxial rotorcraft. Therefore, a better understanding of the capabilities of a lift-offset coaxial counter-rotating rotor with a pusher propeller configuration is achieved through the development of a multidisciplinary rotorcraft simulation methodology. A scalable rotorcraft performance model is then developed. The accuracy of the model is verified with the Harrington's "rotor 1" and the Sikorsky X2TD rotorcraft flight test data. 


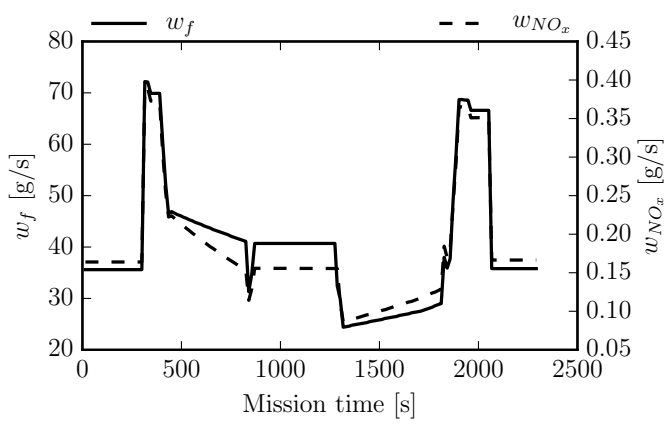

(a) Case A

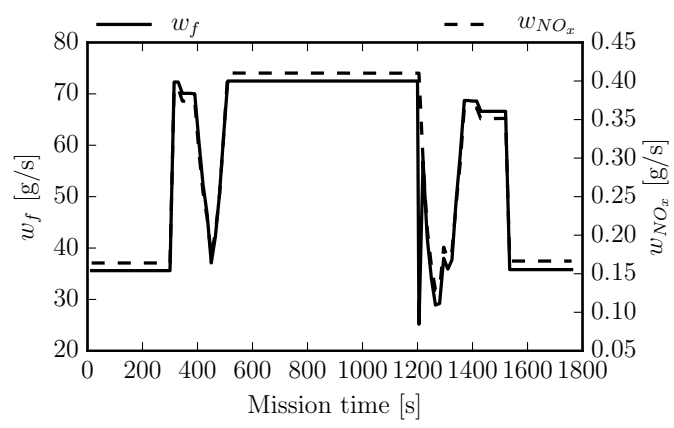

(b) Case C

Figure 23: Engine fuel flow and $N O_{x}$ rate variation with mission time for scenario A (a) and $\mathrm{C}(\mathrm{b})$

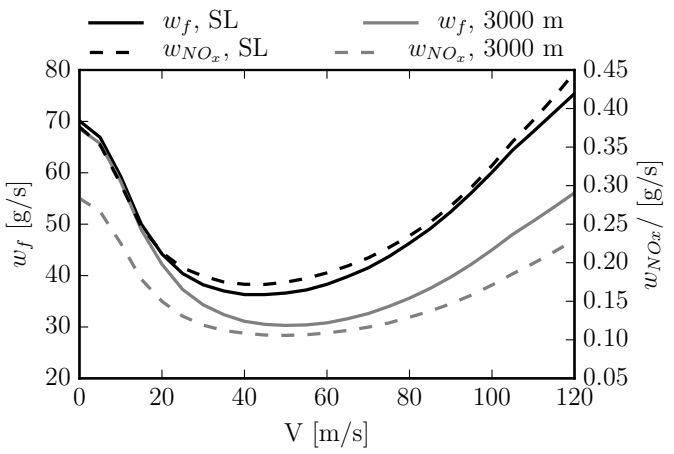

Figure 24: Engine fuel flow and $N O_{x}$ rates versus forward speed and altitude at ISA conditions and AUM $=2700 \mathrm{~kg}$

A conceptual vehicle is designed and its performance and environmental impact evaluated over a notional $100 \mathrm{~km}$ passenger mission leg. A powerplant is modelled after the General Electric T700-GE-700 engine performance and $N O_{x}$ emissions data. Therefore, the engine fuel flow and $N O_{x}$ emissions are evaluated along the scenarios and integrated to obtain the environmental emissions of the vehicle. Cruise speed and altitude effects on mission duration, $N O_{x}$ emissions, and fuel burn are evaluated. Minimum $N O_{x}$ emissions are obtained at relatively low cruise speeds, approximately $80 \mathrm{~m} / \mathrm{s}$ whilst minimum fuel burn was achieved at $90 \mathrm{~m} / \mathrm{s}$. The fuel burn and $N O_{x}$ emissions decreases as the cruise altitude increases. The "optimum" cruise altitude increases as mission leg increases whilst the calculated "optimum" speeds remain unchanged. On the other hand, a fast mission requires flying at high speed and on the shorter possible path, which translates into the lowest possible cruise altitude. Altogether, a trade-off between mission fuel burn, $N O_{x}$ emissions, and mission duration is required. This can be thoroughly investigated within an optimisation framework. Moreover, the other mission segments that remained unchanged during the analysis, should be simultaneously optimised alongside the cruise.

The performance of the herein architecture is representative of fast rotorcraft. The conceptual vehicle had a best range speed of approximately $90 \mathrm{~m} / \mathrm{s}$, representing a $50 \%$ increase from conventional helicopters. This increase is appealing for the future market as it will effectively result in reduce response times and increase of round trips number for a given time. As a consequence, operators will need fewer vehicles and heliports to cover the same areas.

\section{Nomenclature}

\section{Acronyms \& Abbreviation}


$A U M \quad$ All-Up-Mass [kg]

$\mathrm{CO}_{2}$ carbon dioxide

CRPM Coaxial Rotorcraft Performance Model

$N O_{x} \quad$ nitrogen-oxides

ACARE Advisory Council for Aeronautics Research in Europe

HOGE Hover Out of Ground Effect

WGS 84 World Geodetic System date 1984

\section{Roman Symbols}

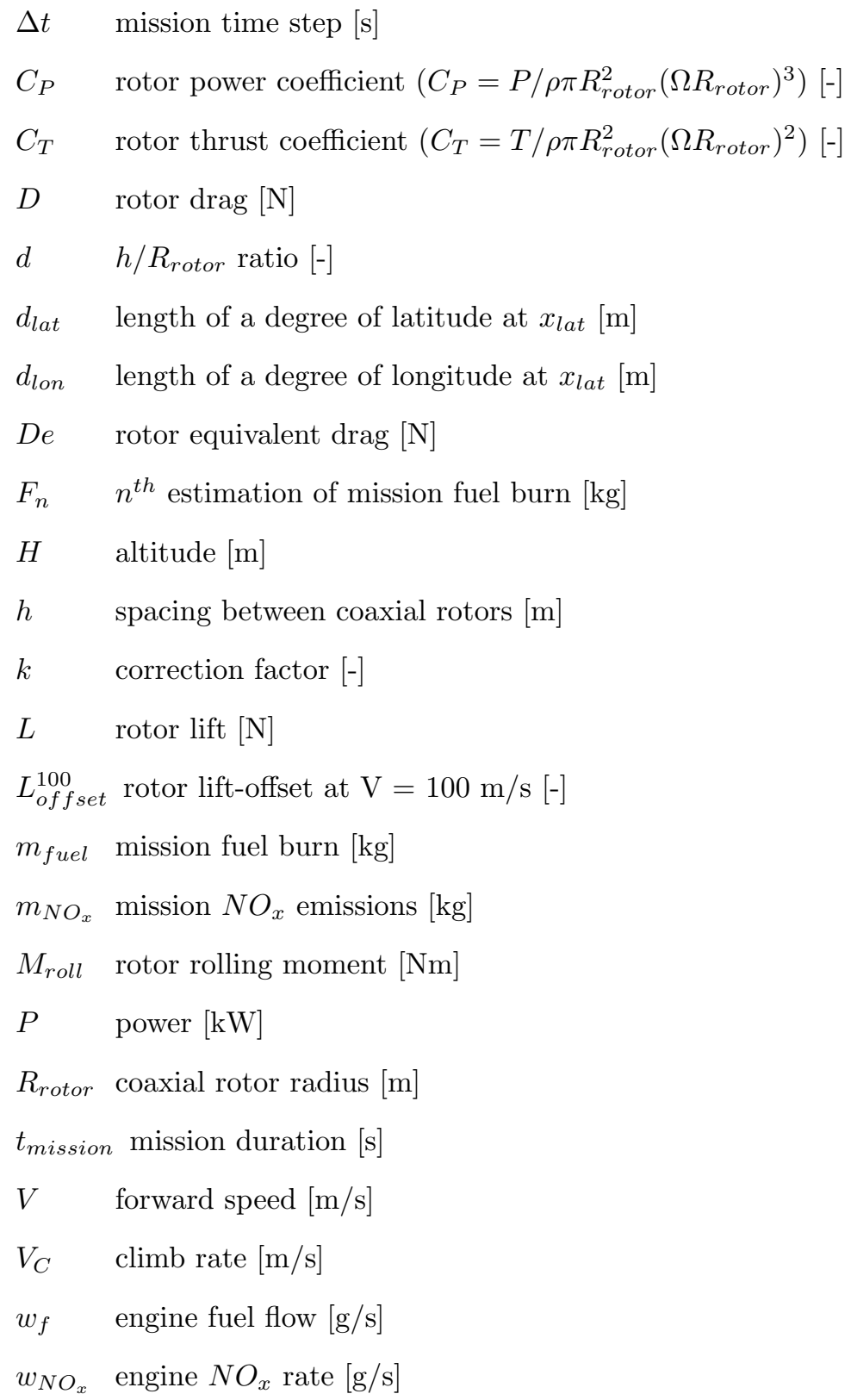


$x_{\text {lat }} \quad$ latitude of reference [degree]

\section{Greek Symbols}

$\alpha \quad$ disc incidence [degree]

$\alpha_{\text {airframe }}$ airframe pitch attitude [rad]

$\chi \quad$ wake skew angle [rad]

$\Gamma \quad$ function with $\chi$ as variable [-]

$\lambda \quad$ rotor inflow [-]

$\lambda_{0} \quad$ rotor uniform inflow velocity [-]

$\lambda_{c} \quad$ climb inflow ratio $\left(V_{C} / \Omega R_{\text {rotor }}\right)[-]$

$\lambda_{h} \quad$ rotor hover inflow [-]

$\lambda_{i} \quad$ rotor induced inflow [-]

$\mu_{x} \quad$ advance ratio $\left(V / \Omega R_{\text {rotor }}\right)[-]$

$\Omega \quad$ rotor rotational speed $[\mathrm{rad} / \mathrm{s}]$

$\psi \quad$ rotor azimuth angle [rad]

$\rho \quad$ air density $\left[\mathrm{kg} / \mathrm{m}^{3}\right]$

$\theta_{0 p} \quad$ Propeller collective [degree]

$\theta_{0} \quad$ rotor collective [degree]

$\theta_{1 C}$ rotor longitudinal cyclic [degree]

$\theta_{1 S} \quad$ rotor lateral cyclic [degree]

$\varepsilon \quad$ fuel estimation error limit [-]

\section{Superscripts}

C climb rate

$H \quad$ flight altitude

$L \quad$ lower rotor of coaxial rotor

$M \quad$ aircraft mass

$U \quad$ upper rotor of coaxial rotor

W wings 


\section{References}

[1] Air Transport Action Group (ATAG), accessed on 19/11/15

URL http://www . atag.org/facts-and-figures.html

[2] Airbus, Global Market Forecast 2016-2035, accessed on 10/11/2016 (2016).

URL http://www .airbus.com/company/market/global-market-forecast-2016-2035/

[3] J. A. Leggett, B. Elias, D. T. Shedd, Aviation and the European Union's Emission Trading Scheme, Tech. rep. (2012). URL https://www.fas.org/sgp/crs/row/R42392.pdf

[4] J.-P. Clarke, The role of advanced air traffic management in reducing the impact of aircraft noise and enabling aviation growth, Journal of Air Transport Management 9 (3) (2003) 161-165.

[5] R. D'Ippolito, J. Stevens, V. Pachidis, A. Berta, I. Goulos, C. Rizzi, A Multidisciplinary Simulation Framework for Optimization of Rotorcraft Operations and Environmental Impact, in: 2nd International Conference on Engineering Optimization (EngOpt 2010), Lisbon, Portugal, September, 2010, pp. 6-9.

[6] Green Rotorcraft, Clean Sky, accessed on 22/08/14 URL http://www.cleansky.eu/green-rotorcraft-grc

[7] P. Brooker, Civil Aircraft Design Priorities: Air Quality? Climate Change? Noise?, The Aeronautical Journal 110(1110) $517-532$.

[8] Sikorsky S-97 RAIDER About, accessed on 15/10/15 URL http://raider.sikorsky.com

[9] D. Walsh, S. Weiner, K. Arifian, T. Lawrence, M. Wilson, T. Millott, R. Blackwell, High Airspeed Testing of the Sikorsky X2 Technology (TM) Demonstrator, in: 67th Annual Forum of American Helicopter Society, Sikorsky Aircraft Corporation, Virginia Beach, 2011.

[10] W. Johnson, J. F. Elmore, E. B. Keen, A. T. Gallaher, G. F. Nunez, Coaxial Compound Helicopter for Compound Urban Operations, AHS Specialists' Conference on Aeromechanics Design for Vertical Lift.

[11] A. Filippone, Flight performance of fixed and rotary wing aircraft, Elsevier aerospace engineering series, Elsevier Ltd., 2006.

[12] G. D. Padfield, Helicopter flight dynamics, 2nd Edition, Vol. 1, Blackwell, Oxford, 2007.

[13] A. S. A. C. Bagai, 64th Annual forum at American Helicopter Society, Montréal, Québec, Canada (2008) 16.

[14] W. Johnson, Influence of Lift Offset on Rotorcraft Performance, AHS Specialists' Conference on Aeromechanics, San Francisco, CA, United States (2008) 31.

[15] W. Johnson, A. M. Moodie, Y. Hyeonsoo, Design and Performance of Lift-Offset Rotorcraft for Short-Haul Missions, in: American Helicopter Society Future Vertical Lift Aircraft Design Conference, National Aeronautics and Space Administration Ames Research Center, Moffett Field, California, DTIC Document, San Francisco, U.S., 2012.

[16] I. Goulos, V. Pachidis, R. DIppolito, J. Stevens, C. Smith, An Integrated Approach for the Multidisciplinary Design of Optimum Rotorcraft Operations, Journal of Engineering for Gas Turbines and Power 134 (9) (2012) 091701.

[17] I. Goulos, P. Giannakakis, V. Pachidis, P. Pilidis, Mission Performance Simulation of Integrated HelicopterEngine Systems Using an Aeroelastic Rotor Model, Journal of Engineering for Gas Turbines and Power 135 (9) (2013) 091201.

[18] W. L. Macmillan, Development of a Module Type Computer Program for the Calculation of Gas Turbine Off Design Performance, Ph.d. thesis, Cranfield University, Cranfield, Bedfordshire, UK (1974).

[19] C. Celis, B. Moss, P. Pilidis, Emissions Modelling for the Optimization of Greener Aircraft Operations, Combustion, Fuels and Emissions 2 (2009) 167-178. doi:10.1115/GT2009-59211

[20] Eurocontrol, Eurocontrol WGS 84 Implementation Manual| Brussels, Belgium, 1998. URL http://www.icao.int/safety/pbn/documentation/eurocontrol/eurocontrolwgs84implementationmanual.pdf

[21] J. G. Leishman, S. Ananthan, An optimum coaxial rotor system for axial flight, Journal of the American Helicopter Society 53 (4) (2008) 366-381.

[22] J. Yana, O. Rand, Performance Analysis of a Coaxial Rotor System in Hover: Three Points of View, Tech. rep., International Congress of the Aeronautical Sciences (2012).

[23] M. Nowak, J. Prasad, D. Peters, Development of a Finite State Model for a Coaxial Rotor in Forward Flight, AHS 70th Annual Forum, Montréal, Québec, Canada.

[24] V. Pachidis, P. Pilidis, L. Marinai, T. Templalexis, Towards a Full Two Dimensional Gas Turbine Performance Simulator, The Aeronautical Journal 111 (1121) (2007) 433-442.

[25] Y.-G. Li, L. Marinai, V. Pachidis, E. L. Gatto, P. Philidis, Multiple-Point Adaptive Performance Simulation Tuned to Aeroengine Test-Bed Data, Journal of Propulsion and Power 25 (3) (2009) 635-641.

[26] I. Goulos, F. Ali, K. Tzanidakis, V. Pachidis, R. D'Ippolito, A Multidisciplinary Approach for the Comprehensive Assessment of Integrated Rotorcraft-Powerplant Systems at Mission Level, Journal of Engineering for Gas Turbines and Power 137 (012603-1) (2015) 11.

[27] R. D. Harrington, Full-Scale-Tunnel Investigation of the Static-Thrust Performance of a Coaxial Helicopter Rotor, Tech. rep. (1951).

[28] H. W. Kim, R. E. Brown, A Comparison of Coaxial and Conventional Rotor Performance, Journal of the American Helicopter Society 55 (1) (2010) 12004.

[29] R. Blackwell, T. Millott, Dynamics Design Characteristics of the Sikorsky X2 TechnologyTM Demonstrator Aircraft, 64th Annual forum at American Helicopter Society, Montréal, Québec, Canada (2008) 13.

[30] W. Johnson, Lift-Offset Compound Design Background, X2TD, JMR ME1A, National Aeronautics and Space Administration, Ames Research Center, Moffett Field, California (2011) 32. 
[31] AVX Aircraft Company, accessed on 30/03/16

URL http://www . avxaircraft.com/

[32] Ballin, M. G., A high fidelity real-time simulation of a small turboshaft engine, Tech. rep., NASA Ames Research Center; Moffett Field, CA, United States (1988). doi:NASA-TM-100991

[33] U. S. Cohen, J. D. (General Electric Co., Lynn, Ma, Analytical fuel property effects, small combustors, phase 1, Tech. rep., NASA-CR-168138 (apr 1983)

[34] T. G. Hill, J. D. Monty, H. L. Morton, Analytical fuel property effects: Small combustors, phase 2, Tech. rep., NASACR-174848 (mar 1985). 
2017-06-15

\title{
Mission performance analysis of a
} conceptual coaxial rotorcraft for air taxi applications

\author{
Enconniere, Julien
}

Elsevier

Enconniere J, Ortiz-Carretero J, Pachidis V. (2017) Mission performance analysis of a conceptual coaxial rotorcraft for air taxi applications. Aerospace Science and Technology,

Volume 69, October 2017, pp. 1-14

http://dx.doi.org/10.1016/j.ast.2017.06.015

Downloaded from Cranfield Library Services E-Repository 